\title{
Left-Right Side-Specific Neuropeptide Mechanism Mediates Contralateral Responses to a Unilateral Brain Injury
}

Hiroyuki Watanabe, 1,* Olga Nosova, 1,* Daniil Sarkisyan, ${ }^{1, *}$ Marlene Storm Andersen, 2,*

(DLiliana Carvalho, ${ }^{3, *}$ DVladimir Galatenko, ${ }^{4}$ Igor Bazov, ${ }^{1}$ Nikolay Lukoyanov, ${ }^{3,5,6}$ Gisela H. Maia, ${ }^{5,6,3}$

Mathias Hallberg, ${ }^{1}$ Mengliang Zhang, ${ }^{2,7}$ (D)ens Schouenborg, ${ }^{7, \#}$ and Georgy Bakalkin ${ }^{1, \#}$

\section{https://doi.org/10.1523/ENEURO.0548-20.2021}

${ }^{1}$ Department of Pharmaceutical Biosciences, Uppsala University, Uppsala, Sweden, $75124,{ }^{2}$ Department of Molecular Medicine, University of Southern Denmark, Odense, Denmark, 5230, ${ }^{3}$ Departamento de Biomedicina da Faculdade de Medicina da Universidade do Porto, Instituto de Investigação e Inovação em Saúde, Instituto de Biologia Molecular e Celular, Porto, Portugal, 4200-135, ${ }^{4}$ Faculty of Mechanics and Mathematics, Lomonosov Moscow State University, Moscow, Russia, 119991, ${ }^{5}$ Medibrain, Vila do Conde, Porto, Portugal, 4480-807, ${ }^{6}$ Brain Research Institute, Porto, Portugal, 4200-135, and ${ }^{7}$ Neuronano Research Center, Department of Experimental Medical Science, Lund University, Lund, Sweden, 22381

\section{Visual Abstract}
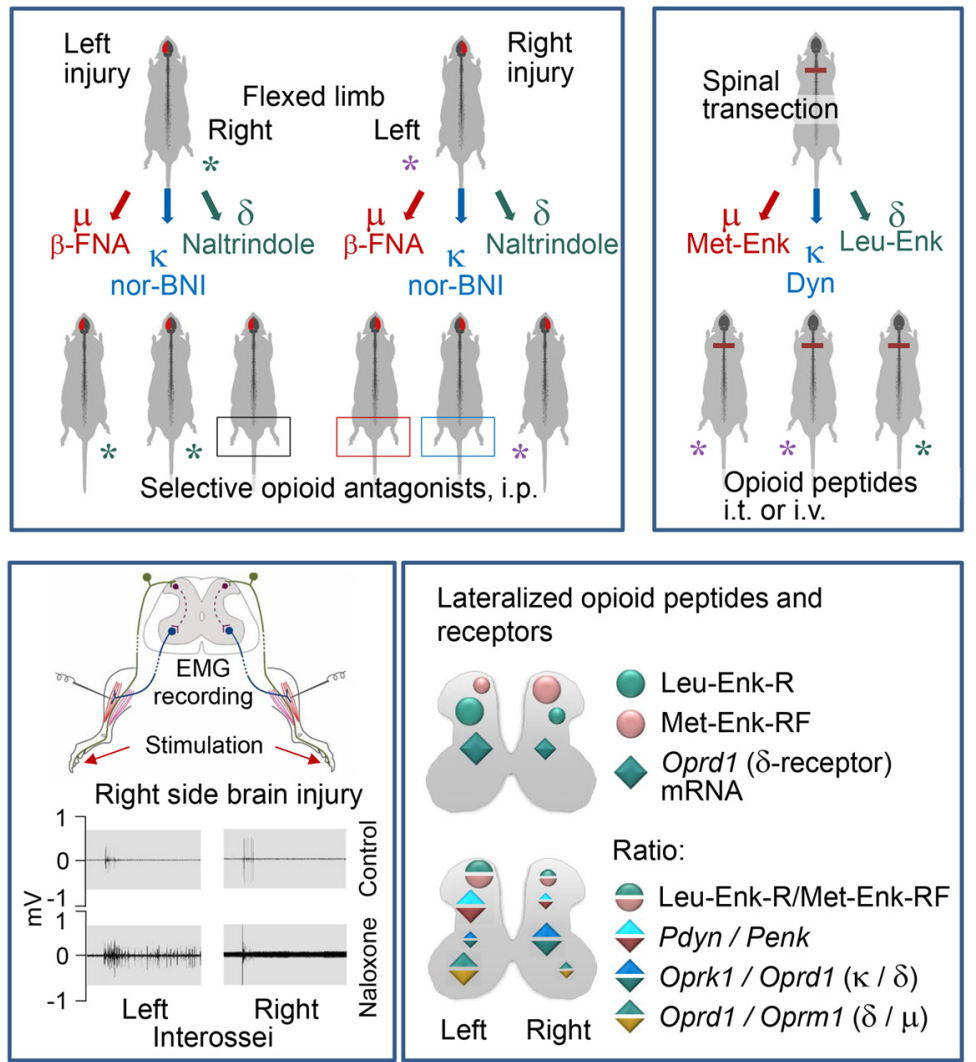

Neuropeptides are implicated in control of lateralized processes in the brain. A unilateral brain injury (UBI) causes the contralesional sensorimotor deficits. To examine whether opioid neuropeptides mediate UBI 


\section{Significance Statement}

Functional specialization of the left and right hemispheres is an organizing principle of the brain. Lasting regulation of lateralized processes may be accomplished by paracrine neurohormonal mechanisms that preferentially operate in the left or right hemisphere. Our findings support this hypothesis by demonstration that mirror-symmetric neural circuits that control the left and right hindlimbs may be regulated by the left-side and right-side specific neuropeptide mechanisms. Neuropeptides may differentially target the left and right counterparts of these circuits, and in this way control the left-right balance in their functional performance. This bipartite mechanism may be based on lateralization of the neuropeptide systems, and may operate in the spinal cord or control neural pathways descending from the brain to contralateral motoneurons.

induced asymmetric processes we compared effects of opioid antagonists on the contralesional and ipsilesional hindlimb responses to the left-sided and right-sided injury in rats. UBI induced hindlimb postural asymmetry (HL-PA) with the contralesional hindlimb flexion, and activated contralesional withdrawal reflex of extensor digitorum longus (EDL) evoked by electrical stimulation and recorded with EMG technique. No effects on the interossei (Int) and peroneaus longus (PL) were evident. The general opioid antagonist naloxone blocked postural effects, did not change EDL asymmetry while uncovered cryptic asymmetry in the PL and Int reflexes induced by UBI. Thus, the spinal opioid system may either mediate or counteract the injury effects. Strikingly, effects of selective opioid antagonists were the injury side-specific. The $\mu$-antagonist $\beta$-funaltrexamine (FNA) and $\kappa$-antagonist nor-binaltorphimine (BNI) reduced postural asymmetry after the right but not left UBI. In contrast, the $\delta$-antagonist naltrindole (NTI) inhibited HL-PA after the left but not right-side brain injury. The opioid gene expression and opioid peptides were lateralized in the lumbar spinal cord, and coordination between expression of the opioid and neuroplasticity-related genes was impaired by UBI that together may underlie the side-specific effects of the antagonists. We suggest that mirror-symmetric neural circuits that mediate effects of left and right brain injury on the contralesional hindlimbs are differentially controlled by the lateralized opioid system.

Key words: brain injury; postural asymmetry; withdrawal reflexes; opioid system; left-right side-specific regulation

\section{Introduction}

External symmetry and functional specialization of the left and right hemispheres are a fundamental principle of nervous system organization in bilaterians (Craig, 2005; MacNeilage et al., 2009; Concha et al., 2012; Duboc et al.,

Received December 16, 2020; accepted April 1, 2021; First published April 26, 2021.

The authors declare no competing financial interests.

Author contributions: N.L., M.H., M.Z., J.S., and G.B. designed research; H.W., O.N., M.S.A., L.C., I.B., N.L., and G.H.M. performed research; H.W., O.N., D.S., V.G., N.L., M.Z., J.S., and G.B. analyzed data; O.N. and G.B. wrote the paper.

The work was supported by Swedish Research Council Grants K2014-62X12190-19-5 and 2019-01771-3 (to G.B.) and 2016-06195 (to J.S.), L. Hiertas Minne Foundation and P.O. Zetterling Foundation (to O.N.), Uppsala University (to G.B.), Lund University and Skåne County Council Grant F2018/1490 (to J.S.), and the Government of the Russian Federation Grant 14.W03.31.0031 (to V.G.).

${ }^{*}$ H.W., O.N., D.S., M.S.A., and L.C. contributed equally to this work. \#J.S. and G.B. are co-senior authors.

V. Galatenko's present address: Evotec International GmbH, Göttingen, Germany.

Acknowledgements: We thank Dr. Michael Ossipov for discussion and manuscript processing.

Correspondence should be addressed to Georgy Bakalkin at georgy. bakalkin@farmbio.uu.se.

https://doi.org/10.1523/ENEURO.0548-20.2021

Copyright @ 2021 Watanabe et al.

This is an open-access article distributed under the terms of the Creative Commons Attribution 4.0 International license, which permits unrestricted use, distribution and reproduction in any medium provided that the original work is properly attributed.
2015; Güntürkün and Ocklenburg, 2017). Language, spatial cognition, motor functions, emotions, and pain are lateralized. Asymmetries of neural circuits of the left and right hemisphere subserving these functions may be a basis for the lateralization of these functions (Concha et al., 2012; Gotts et al., 2013; Caeyenberghs and Leemans, 2014; Horstick et al., 2020).

Several studies suggest that the lateralized neural circuits are controlled by local paracrine regulators, including neuropeptides and neurotransmitters that operate either on the left or right side (Deliagina et al., 2000; Kawakami et al., 2003; Zink et al., 2011; Hussain et al., 2012; Marlin et al., 2015; Watanabe et al., 2015; Kononenko et al., 2017, 2018; Nation et al., 2018; Phelps et al., 2019). Thus, oxytocin enables retrieval behavior by enhancing responses of the left but not right auditory cortex (Marlin et al., 2015), while the dynorphin- $\kappa$-opioid system controls processing of pain in the right but not left amygdala (Nation et al., 2018; Phelps et al., 2019). Intriguing questions are whether there is a bipartite neurohormonal mechanism that selectively regulates the processes lateralized to the left and to the right, and whether this mechanism may have a more general role and control mirror symmetric neurocircuits by selective targeting their left and right counterparts in bilaterally symmetric animals. Such a mechanism may operate locally (e.g., within the cortex), or at several levels along the neuraxis where it 
can balance activity of neural pathways that convey leftright-specific signals, for example, from the cerebral hemispheres to contralateral spinal motoneurons. In this scenario, impairment of the left or right counterpart of this bipartite neurohormonal mechanism by a unilateral brain injury (UBI) may disrupt the left-right balance and lead to asymmetric functional changes.

Traumatic brain injury (TBI) and stroke in patients cause postural and sensorimotor deficits that are generally contralesional and include asymmetric posture and asymmetric exacerbated withdrawal reflexes (Dewald et al., 1999; Spaich et al., 2006, 2014; Serrao et al., 2012; Wilson et al., 2017; Jamal et al., 2018). Consistently, a unilateral injury to the hindlimb sensorimotor cortex in experimental animals induces the hindlimb postural asymmetry (HL-PA) with contralesional limb flexion and asymmetry of the nociceptive withdrawal reflexes (NWRs) with greater activity on the contralesional versus ipsilesional side (Zhang et al., 2020).

Opioid peptides and receptors in the spinal cord are involved in regulation of withdrawal reflexes, sensory processes and motor functions (Clarke et al., 1992; Faber et al., 1997; Fujibayashi et al., 1998; Jankowska and Schomburg, 1998; Steffens and Schomburg, 2011; Wang et al., 2018). Previous studies demonstrated that in animals with intact brains opioid peptides and synthetic opioids mimic the effects of a unilateral brain lesion by inducing HL-PA with flexion on the side that was determined by the type of opioid agonist administered (Bakalkin et al., 1980, 1986; Chazov et al., 1981; Bakalkin and Kobylyansky, 1989; Watanabe et al., 2020). The $\kappa$ - and $\delta$-agonists induced flexion of the left and right hindlimb, respectively.

We hypothesize that the endogenous opioid peptides may function as a bipartite neurohormonal system that selectively regulates the left and right sided processes, and, by this virtue, they may differentially control the effects of the left and right UBI on the contra-ipsilesional postural and sensorimotor hindlimb responses. To test this hypothesis, we examine whether the effects of a focal unilateral injury of the hindlimb sensorimotor cortex on the formation of HL-PA and asymmetry in hindlimb NWRs are mediated through the opioid system; whether this system is lateralized in the spinal cord; and whether opioid receptor subtypes selectively mediate the effects of the left and right side UBI on HL-PA formation. Identifying neurohormonal and neurotransmitter mechanisms that convey the left-side and right-side specific messages is important for a basic understanding of the nervous system, and development of pharmacotherapy to target asymmetric postural and sensorimotor deficits secondary to TBI and stroke.

\section{Materials and Methods}

\section{Animals}

Adult male Sprague Dawley rats (Taconic) weighing 200-430 g were used in the study. The animals received food and water ad libitum, and were kept in a 12/12 h light/dark cycle (light on from 10 A.M. to 10 P.M.) at a constant environmental temperature of $21^{\circ} \mathrm{C}$ (humidity: $65 \%)$ and randomly assigned to their respective experimental groups. Animal experiments ware approved by local ethical committee. Experiments were performed from 9 A.M. to 4 P.M., besides electrophysiological experiments that were conducted from 9 A.M. to $\sim 8$ P.M. After the experiments were completed, the animals were given a lethal dose of pentobarbital.

\section{Brain surgery and histology}

The rats were anesthetized with $3 \%$ isoflurane (Abbott) in a mixture with $65 \%$ nitrous oxide and $35 \%$ oxygen. Core temperature of the animals was controlled using a feedback-regulated heating system. In the experiments involving electrophysiological recordings, an infusion of $5 \%$ glucose in Ringer acetate $(\mathrm{pH} 7.0)$ at a rate of 5$100 \mu \mathrm{l} / \mathrm{min}$ was administered via the right jugular vein, and the rats were ventilated artificially via a tracheal cannula and the expiratory $\mathrm{CO}_{2}$ and mean arterial blood pressure $(65-140 \mathrm{mmHg})$ was monitored continuously in the right carotid artery.

The rat head was fixed in a position in which the bregma and $\lambda$ were located at the same horizontal level. After local injection of lidocaine (xylocaine, $3.5 \mathrm{mg} / \mathrm{ml}$ ) with adrenaline $(2.2 \mu \mathrm{g} / \mathrm{ml})$, the scalp was cut open and a piece of the parietal bone located $0.5-4.0 \mathrm{~mm}$ posterior to the bregma and 1.8-3.8 lateral to the midline (Paxinos and Watson, 2007) was removed. The part of the cerebral cortex located below the opening that includes the hind-limb representation area of the sensorimotor cortex was aspirated with a metallic pipette (tip diameter $0.5 \mathrm{~mm}$ ) connected to an electrical suction machine (Craft Duo-Vec Suction unit, Rocket Medical Plc; Zhang et al., 2020). Care was taken to avoid damaging the white matter below the cortex. After the ablation, bleeding was stopped with a piece of Spongostone and the bone opening was covered with a piece of TissuDura (Baxter). For sham operations, animals underwent the same anesthesia and surgical procedures, but the cortex was not ablated.

Localization and size of cortical lesions were analyzed in rats with left side $(n=10)$ and right side $(n=11)$ UBI 6$18 \mathrm{~d}$ after injury. After perfusion with $4 \%$ paraformaldehyde the brain was removed and postfixed in the same fixative overnight. Then the brain was soaked in phosphate-buffered saline with $30 \%$ sucrose for $48 \mathrm{~h}$, dissected into blocks which were then sliced into $50-\mu \mathrm{m}$ sections with a freezing microtome. Every fourth section was stained with toluidine (Nissl stain), and all the stained sections across the lesion site were photographed and the rostrocaudal respective mediolateral extension as well as lesion volume were calculated.

\section{Analysis of HL-PA}

The magnitude of postural asymmetry (MPA) and the side of the flexed limb were assessed as described elsewhere (Bakalkin and Kobylyansky, 1989; Watanabe et al., 2020; Zhang et al., 2020). Briefly, the measurements were performed under pentobarbital $(60 \mathrm{mg} / \mathrm{kg}$, i.p.) or isoflurane $(1.5 \%$ isoflurane in a mixture of $65 \%$ nitrous oxide 
and $35 \%$ oxygen) anesthesia that yielded the same results. The level of anesthesia was characterized by a barely perceptible corneal reflex and a lack of overall muscle tone. The rat was placed in the prone position on the 1-mm grid paper, and the hip and knee joints were straightened by gently pulling the hindlimbs backwards for $1 \mathrm{~cm}$ to reach the same level. Then, the hindlimbs were set free and the MPA was measured in millimeters as the length of the projection of the line connecting symmetric hindlimb distal points (digits 2-4) on the longitudinal axis of the rat. The procedure was repeated six times in immediate succession, and the mean HL-PA value for a given rat was used in statistical analyses. The rat was regarded as asymmetric if the magnitude of HL-PA exceeded the 2$\mathrm{mm}$ threshold (see statistical section). The limb displacing shorter projection was considered as flexed.

In a subset of the rats HL-PA was assessed by the hands-off method. Silk threads were glued to the nails of the middle three toes of both hindlimbs, and their other ends were tied to hooks attached to the movable platform that was operated by a micromanipulator. Positions of the limbs were adjusted to the same, symmetric level, and stretching was performed for a distance of $1-1.5 \mathrm{~cm}$ at a rate of $2 \mathrm{~cm} / \mathrm{s}$. The threads then were relaxed, the limbs were set free and the resulting HL-PA was photographically recorded. The procedure was repeated six times in succession, and the mean value of postural asymmetry for a given rat was used in statistical analyses. The hands-on and hands-off procedures yielded the same HL-PA magnitude and direction; the MPA correlated with the asymmetry of the force applied to stretch the contralesional and ipsilesional hindlimbs (Watanabe $\mathrm{H}$ and Bakalkin $\mathrm{G}$, unpublished observations; Zhang et al., 2020). Experimenters were blinded to the experimental conditions where possible.

\section{Spinal cord transection and decerebration}

The animals were anesthetized with sodium pentobarbital (i.p.; $60 \mathrm{mg} / \mathrm{kg}$ body weight, as an initial dose and then $6 \mathrm{mg} / \mathrm{kg}$ every hour), or with isoflurane (1.5\% isoflurane in a mixture of $65 \%$ nitrous oxide and $35 \%$ oxygen) anesthesia. After measurement of postural asymmetry, the rats were placed on a stereotaxic frame to maintain the body temperature at $37 \pm 0.3^{\circ} \mathrm{C}$ with a heating pad connected by a rectal probe (CMA150, CMA). A laminectomy at the thoracic T2-T3 level was conducted and the spinal cord was completely transected between the ligatures. Local infiltration of $3.5 \mathrm{mg} / \mathrm{ml}$ lidocaine (xylocaine) with $2.2 \mu \mathrm{g} / \mathrm{ml}$ adrenaline was used to reduce nociceptive input during surgery. The completeness of the transection was confirmed by (1) inspecting the cord under microscope during the operation to ensure that no spared fibers bridged the transection site and that the rostral and caudal stumps of the spinal cord are completely retracted; (2) placing a piece of Spongostan (Medispon; MDD) between the rostral and caudal stumps of the spinal cord; and (3) examining the spinal cord after termination of the experiment. After completion of surgical procedures, the wounds were closed with 3-0 suture (AgnTho's) and rats were kept under infrared radiation lamp to maintain body temperature during monitoring of postural asymmetry.

The decerebration procedure was described elsewhere (Dobson and Harris, 2012). After a craniotomy, the brain rostral to the inferior colliculus was removed with an electrical surgical suction machine (New Askir 20, MedicalExpo). Bleeding was stopped with Meditamp Extra (MDD Dedical Devices). The anesthesia was then discontinued. Experiments were terminated on signs of deterioration, such as a precipitous drop in blood pressure or rise in expiratory $\mathrm{CO}_{2}$ level.

\section{EMG experiments}

Four groups consisted of 39 rats including 11 sham and $14 \mathrm{UBI}$ not treated (control) rats, and seven sham and seven $\mathrm{UBI}$ rats treated with naloxone rats were analyzed between third and sixth day after UBI or sham surgery. The number of animals which data were used in statistical analysis is shown in Extended Data Figure 3-1.

\section{Electromyography recordings}

Core temperature was maintained between 36 and $38^{\circ}$ C using a thermostatically controlled, feedback-regulated heating system. The EMG activity of the extensor digitorum longus (EDL), interossei (Int), and peroneaus longus (PL) muscles of both hindlimbs were recorded. EMG analysis was initiated within $\sim 3 \mathrm{~h}$ after spinalization and decerebration. Recordings were performed using gauge stainless steel disposable monopolar electrodes (DTM-1.00F, The Electrode Store). The electrodes were insulated with Teflon except for $\sim 200 \mu \mathrm{m}$ at the tip. The impedance of the electrodes was from 200 to $1000 \mathrm{k} \Omega$. For EMG recordings, a small opening was made in the skin overlying the muscle, and the electrode was inserted into the mid-region of each muscle belly. A reference electrode was inserted subcutaneously in an adjacent skin region. The electrode position was checked by passing trains $(100 \mathrm{~Hz}, 200 \mathrm{~ms})$ of cathodal pulses (amplitude $<30 \mu \mathrm{A}$, duration $0.2 \mathrm{~ms}$ ). The EMG signal was recorded with Spike 2 program (CED) with a sampling rate of $5000 \mathrm{~Hz}$. Low and high pass filter was set at 50,000 and $500 \mathrm{~Hz}$, respectively. Generally, the EMG activity of two or three pairs of hindlimb muscles was recorded simultaneously in each experiment/rat.

\section{Cutaneous stimulation}

Stimulation sites were decided according to each muscle's receptive field (Schouenborg et al., 1992; Weng and Schouenborg, 1996). After searching the receptive field of each muscle in responding to pinch stimulation, a pair of stimulation electrodes that were the same as the recording electrodes were inserted subcutaneously into the center of each muscle's receptive field. The same pairs of digits (i.e., 2, 3, 4, and 5) of both limbs were stimulated to induce ipsilateral reflex responses (Schouenborg et al., 1992). To detect the stimulation intensity that induce the maximal reflex in each muscle, graded current pulses $(1 \mathrm{~ms}, 0.1 \mathrm{~Hz})$ were used ranging mostly from 1$30 \mathrm{~mA}$, occasionally up to $50 \mathrm{~mA}$. The reflex threshold was defined as the lowest stimulation current intensity evoking a response at least in three out of five stimulations. If a muscle response was induced by stimulation at 
more than one site, the lowest current was taken as a threshold value. For EMG data collection, the current level that induced submaximal EMG responses from both legs, usually at 5-20 mA was chosen. This was usually two to three times higher than the threshold currents. The same current level was used on symmetrical points from the most sensitive area on both paws. For each site EMG responses from 18-20 stimulations at $0.1-\mathrm{Hz}$ frequency were collected. No visible damage of the skin, or marked changes in response properties at the stimulation sites, were detectable at these intensities.

\section{EMG data analysis}

The spikes from Spike2 EMG data files were sorted with Offline Sorter (version 3, Plexon). The EMG amplitude (spike number) from different muscles was calculated with NeuroExplorer (Nex Technologies). To avoid stimulation artifacts, spikes from the first one or two stimulations were removed from further analysis. The number of spikes was calculated from 16 consecutive stimulations thereafter. The EMG thresholds and responses registered from 0.2 to $1.0 \mathrm{~s}$ were analyzed. In this animal preparation, the withdrawal reflexes evoked by innocuous stimulation were very weak compared with those evoked by noxious stimulation (Schouenborg et al., 1992; Weng and Schouenborg, 1998; Schouenborg, 2002; Zhang et al., 2020).

\section{Criteria for comparison of the left and right hindlimbs}

Strict criteria were applied to ensure data comparability between two hindlimbs for (1) the experimental procedures including the symmetry of stimulation and recording conditions between the two sides; (2) application of electrodes with similar resistance for analysis of symmetric muscles; (3) selection of the reflex characteristics for the analysis; and (4) statistical analysis. The core criteria were similar with those described previously (Hultborn and Malmsten, 1983a,b; Malmsten, 1983). Pairs of each stimulation and recording electrodes were positioned as symmetrically as possible. Stimulation electrodes were inserted into the center of the receptive fields of the left and right muscles (Schouenborg et al., 1992; Weng and Schouenborg, 1996), and recording electrodes into the middle portion of the muscle belly. This was performed by an experienced investigator with knowledge in anatomy and physiology. The same stimulation patterns were used for stimulation of pairs of digits to induce reflexes in symmetric muscles. The same threshold level was used for the left and right muscles. In general, the current level that was applied exceeded by 2- to 3-fold the higher threshold recorded for a muscle in the pair at a given stimulation site. Data recorded with stimulation of more than one site (digits 2, 3, 4, and 5) were processed as replicates to decrease experimental error. Only ipsilateral responses were recorded. Only data for pairs of muscles of the same animal were included in the analysis.

To minimize interindividual variations that may be caused by differences in physiological and experimental conditions, including depth of anesthesia, and circulatory and respiratory states, the asymmetry index calculated for each animal but not absolute values of the reflex size (i.e., reflex amplitude, thresholds and the number of spikes), was analyzed. Comparison between the left and right sides using the asymmetry index was based on the assumption that one side was a reference for the other side in each animal, and this approach largely diminished contributions of the interindividual variations (Hultborn and Malmsten, 1983a,b; Malmsten, 1983).

Analysis of the asymmetry index allowed double assessment, first, within each UBI and control (sham surgery) group that identified the asymmetric versus symmetric pattern for a given group; and, second, between the animal groups that revealed the UBI versus sham surgery differences, and the naloxone versus control differences. Analysis of the asymmetry index in the control group established whether the observed distribution was close to the expected symmetric patterns (that is the assessment of the size of variations around the symmetry point) and, therefore, demonstrated the validity of the approach.

Because multiple responses were measured for the same animal, including two limbs, three muscles, and differing stimulation conditions, and because they were analyzed within animal groups and between the groups treated with and without naloxone, we applied mixed-effects models using Bayesian inference. To avoid bias in the acquisition of experimental observations that may be imposed by intermediate data analyses, the data processing and statistical analysis were performed after completion of all experiments.

\section{Analysis of gene expression}

Intact rats and rats exposed to the left-side or right-side UBI or the left-side or right-side sham surgery (five groups; $n=10$ /group) were killed by decapitation on day 3 after the injury. The lumbar spinal cord was dissected into the left and right halves. The tissue samples were snap frozen and stored at $-80^{\circ} \mathrm{C}$ until assay. In the replication study two independent groups of rats with the left shaminjury ( $n=11)$ and left UBI ( $n=12$ rats) were used in analysis of lateralization.

\section{Quantitative RT-PCR}

Total RNA was purified by using RNeasy Lipid Tissue Mini kit (QIAGEN). RNA concentrations were measured with Nanodrop (Nanodrop Technologies). RNA (500 ng) was reverse-transcribed to cDNA with the cDNA iScript kit (Bio-Rad Laboratories) according to manufacturer's protocol. cDNA samples were aliquoted and stored at $-20^{\circ} \mathrm{C}$. The cDNAs were mixed with PrimePCR Probe assay (Extended Data Fig. 5-1) and iTaq Universal Probes supermix (Bio-Rad Laboratories) for qPCR with a CFX384 Touch Real-Time PCR Detection System (Bio-Rad Laboratories) according to the manufacturer's instructions. The following conditions were applied for the 2-step real-time PCR reaction: $3 \mathrm{~min}$ at $95^{\circ} \mathrm{C}$, then 40 cycles for 5 $\mathrm{s}$ at $95^{\circ} \mathrm{C}$, followed by incubation for $30 \mathrm{~s}$ at $60^{\circ} \mathrm{C}$.

All quantitative RT-PCR procedures were conducted strictly in accordance with the established guidelines for the qRCR based analysis of gene expression, the minimum information for publication of quantitative real-time 
PCR experiments guidelines (MIQE; Bustin et al., 2009; Taylor et al., 2019). The raw qRT-qPCR data were obtained by the CFX Maestro Software for CFX384 Touch Real-Time PCR Detection System (Bio-Rad Laboratories). The mRNA levels of genes of interest were normalized to the geometric mean of expression levels of two reference genes Actb and Gapdh selected out of 10 genes (Actb, B2m, Gapdh, Gusb, Hprt, Pgk, Ppia, Rplpo13a, Tbp, and Tfrc), using the geNorm program (https://genorm.cmgg. be/; Vandesompele et al., 2002; Kononenko et al., 2017, 2018). The expression stability of candidate reference genes was computed for ten sets of samples that were the left and right halves of the lumbar spinal cord obtained from intact rats, left-sided and right-sided sham surgery groups, and the left-sided and right-sided UBI groups, and was as follows (from high to low): Actb, Gapdh, Tbp, Rplpo13a, Hprt, Pgk, B2m, Tfrc, Ppia, and Gusb. In each experiment, the internal reference gene-stability measure $M$ value did not exceed the 1.5 threshold value imposed by the MIQE. The number of reference genes was optimized using the pairwise stability measure ( $V$ value) calculated by the geNorm program. The $\mathrm{V}$ value for Actb and Gapdh, the top reference genes did not exceed the 0.15 threshold demonstrating that analysis of these two genes is sufficient for normalization.

A proportion in the expression of subtypes of opioid receptor genes and those in the opioid peptide precursor genes were analyzed as the Oprd1/Oprm1, Oprk1/Oprd1, and Oprk1/Oprm1 ratio, and the Pdyn/Penk ratio, respectively. These ratios did not depend on expression levels of reference gens and normalization procedure.

\section{Neuroplasticity-related genes (Extended Data Fig. 5-1)}

Arc, activity-regulated cytoskeletal gene implicated in numerous plasticity paradigms; $B d n f$, brain-derived neurotrophic factor regulating synaptogenesis; $c F o s$, a neuronal activity dependent transcription factor; Dlg4 gene codes for PSD95 involved in AMPA receptor-mediated synaptic plasticity and post-NMDA receptor activation events; Egr1 regulating transcription of growth factors, DNA damage, and ischemia genes; Gap-43 coding for growth-associated protein Gap-43 that regulates axonal growth and neural network formation; GluR1 and Grin2b coding for the glutamate ionotropic receptor AMPA type Subunit 1 and NMDA receptor subunit, respectively, both involved in glutamate signaling and synaptic plasticity; Grin2a subunit of the glutamate receptors that regulates formation of neural circuits and their plasticity; Homer-1 giving rise to Homer Scaffold Protein 1, a component of glutamate signaling involved in nociceptive plasticity; Nfkbia (I- $\kappa$-B- $\alpha$ ) that inhibits NF- $\kappa$-B/REL complexes regulating activity-dependent inhibitory and excitatory neuronal function; Syt4 (synaptotagmin 4) playing a role in dendrite formation and synaptic growth and plasticity; and Tgfb1 that gives rise to transforming growth factor $\beta 1$ regulating inflammation, expression of neuropeptides and glutamate neurotoxicity, were selected as representatives of neuroplasticity-related genes (Anderson and Winterson, 1995; Hayashi et al., 2000; Buisson et al., 2003; Joynes et al., 2004; You et al., 2004; Adkins et al., 2006; O'Mahony et al., 2006; Tappe et al., 2006; Vavrek et al., 2006; Larsson and Broman, 2008; Dolan et al., 2011; Santibañez et al., 2011; Grasselli and Strata, 2013; Harris et al., 2016; Won et al., 2016; Epstein and Finkbeiner, 2018).

\section{Radioimmunoassay (RIA)}

The procedure was described elsewhere (ChristenssonNylander et al., 1985; Merg et al., 2006). Briefly, $1 \mathrm{M}$ hot acetic acid was added to finely powdered frozen tissues, and samples were boiled for $5 \mathrm{~min}$, ultrasonicated and centrifuged. Tissue extract was run through SP-Sephadex ion exchange C-25 column, and peptides were eluted and analyzed by RIA. Cross-reactivity of Leu-enkephalin-Arg (LER) antiserum with dynorphin B and Leu- and Met-enkephalin was $<0.1 \%$ molar, with $\alpha$-neoendorphin $0.5 \%$ molar, with Dynorphin A (1-8) 0.7\% molar, with Met-enkephalin-Arg-Phe (MEAP) 1\% molar and with Met-enkephalin-Arg 10\% molar. Cross-reactivity of MEAP antiserum with Met-enkephalin, Met-enkephalin-Arg, Met-enkephalin-ArgGly-Leu, Leu-enkephalin and LER was $<0.1 \%$ molar (Nylander et al., 1997). This RIA variant readily detected LER in wild-type mice (Nguyen et al., 2005) but not in Pdyn knock-out mice; thus the assay was highly specific and not sensitive to the presence of contaminants. The peptide content is presented in $\mathrm{fmol} / \mathrm{mg}$ tissue. No normalization per amount of tissue was performed for calculation of the LER/ MEAP ratio that therefore was free of any bias because of differences in amount of tissue between the analyzed animal groups, and between the left and right spinal halves.

\section{Experimental time line/drug treatment design (Fig. 1)}

The HL-PA in UBI rats was analyzed before and after antagonist administration. The rats with the MPA $>2 \mathrm{~mm}$ were defined as asymmetric; the 2-mm MPA was 94th percentile after the sham surgery. Rats that were defined as asymmetric ( $89 \%$ in UBI group) on day 1 , were used for the following analysis of the antagonists or saline.

\section{Design 1}

HL-PA induced by the left or right-side UBI and its time course. The HL-PA was examined on days $1,3,6,7$, and 8 after the UBI, and on days 1 and 3 after sham surgery.

\section{Design 2}

Analysis of effects of naloxone, naltrindole (NTI) and saline. HL-PA formation in rats with the left or right-side UBI was examined on day 1 (control measurement 1 ), and then before (control measurement 2) and $30 \mathrm{~min}$ after administration of naloxone, NTI, or saline on day 3,5 , or 7 after the operation.

\section{Design 3}

Analysis of effects of nor-binaltorphimine (nor-BNI) and $\beta$-funaltrexamine $(\beta-\mathrm{FNA})$. Antagonists were administered $1 \mathrm{~d}$ before HL-PA analysis that was conducted on day 3,5 , or 7 after the left or right-side UBI. Control HLPA measurement was performed on day 1 .

\section{Design 4}

Comparison of HL-PA in rats before and after transection of the spinal cord. Effects of naloxone on the HL-PA 
in rats with transected spinal cord. The spinal cord was transected on day $7 ; \mathrm{HL}-\mathrm{PA}$ was measured before and $1 \mathrm{~h}$ after the transection and then naloxone or saline were administered and HL-PA was analyzed 30 min later.

Naloxone (10 mg/kg, i.p.), NTI (5 mg/kg, i.p.), and saline were administered $30 \mathrm{~min}$ before analysis of $\mathrm{HL}-\mathrm{PA}$, while nor-BNI $(6 \mathrm{mg} / \mathrm{kg}$, s.c.) and $\beta$-FNA ( $3 \mathrm{mg} / \mathrm{kg}$, s.c.) $1 \mathrm{~d}$ before the analysis. In the EMG experiments, naloxone $(10 \mathrm{mg} / \mathrm{kg})$ was infused $30 \mathrm{~min}$ before the analysis.

Doses and timeline for naloxone (Norris et al., 2009), NTI (Petrillo et al., 2003; Nizhnikov et al., 2009; Rutten et al., 2018), nor-BNI (Horan et al., 1992; Patkar et al., 2013; Rutten et al., 2018) and $\beta$-FNA (Petrillo et al., 2003) were robustly established in previous studies to block the respective receptors. The dose for naloxone was chosen to block all three subtypes of opioid receptors. nor-BNI and $\beta$-FNA exert long-lasting antagonistic effects that persist for at least one month and are receptor selective from day 1 after administration.

\section{Statistical analysis}

\section{$H L-P A$ and electrophysiology}

Processing and statistical analysis of the HL-PA, EMG, and molecular data were performed after completion of the experiments by the statisticians, who were not involved in execution of experiments. Therefore, the results of intermediate statistical analyses could not affect acquisition of experimental data.

Postural asymmetry and EMG data were analyzed using Bayesian regression models via full Bayesian framework by calling Stan 2.21 (Carpenter et al., 2017) from $R$ 3.6.3 R Core Team using the brms 2.12 (Burkner, 2017) interface. Predictors and outcomes were centered and scaled. To reduce the influence of outliers, models used Student's $t$ response distribution family with identity link function. Models had no intercepts with indexing approach to predictors (McElreath, 2019). According to Stan recommendations (Gelman, 2019) weakly informative priors were used for group-level effects, residual SD and group-level SD $p$ values, adjusted using the multivariate $t$ distribution with the same covariance structure as the estimates, were produced by frequentist summary in emmeans 1.4.6 (Searle et al., 1980). Medians of the posterior distribution and $95 \%$ highest posterior density continuous intervals (HPDCls) were plotted. The contrast between groups was defined as significant if both $95 \% \mathrm{HPDCl}$ did not include zero and adjusted $p$ value was $\leq 0.05$.

\section{Gene expression and peptides}

The mRNA levels of the endogenous opioid system genes (Pdyn, Penk, Oprk1, Oprd1, and Oprm1) and the levels of opioid peptides (LER, MEAP) in the left and right halves of the lumbar spinal cord were compared among the five rat groups that were control (intact), left side sham, right side sham, left side UBI and right side UBI) rats, respectively. The gene/gene ratios including Oprk1/Oprd1, Oprk1/ Oprm1, Oprd1/Oprm1, Pdyn/Penk ratios and the LER/ MEAP ratio were also compared between the groups. The Kolmogorov-Smirnov and Levene's tests revealed deviations from normality and differences in the variances

\section{UBI or Sham $\nabla$ Drug treatment \\ Spinal transection $\bullet$ HL-PA analysis}

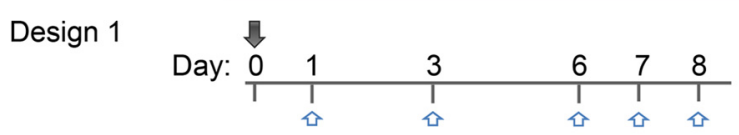

Design 2 UBI Naloxone

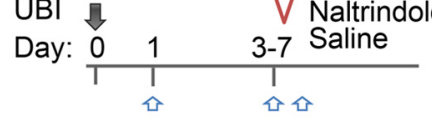

$\nabla$ nor-BNI

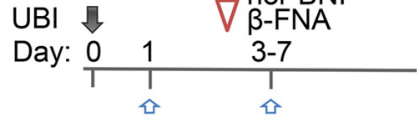

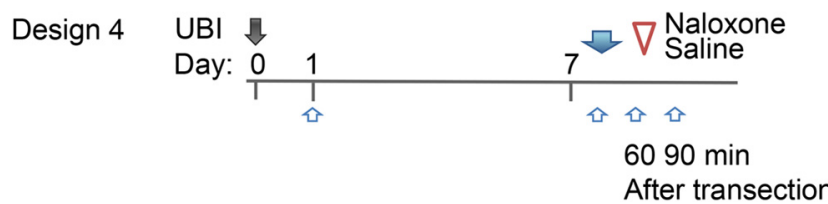

Figure 1. An experimental design. Rats received UBI or sham surgery on day 0 . HL-PA was analyzed before and after treatment with opioid antagonists or saline; and before and after complete spinal cord transection. In design 1, a time course of HL-PA after the UBI or sham surgery was analyzed. In design 2, naloxone, NTI, or saline were injected to the left-side and rightside UBI rats. HL-PA was evaluated on day 1 , and on the test day before and 30 min after the injection. In design 3 , effects of nor-BNI and $\beta$-FNA on HL-PA induced by the left-side or rightside UBI were analyzed; the antagonists were administered $1 \mathrm{~d}$ before the analysis. In design 4, effects of spinal cord transection, and effects of naloxone in rats with transected spinal cord on the HL-PA were examined.

between the rat groups, respectively, for several genes and peptides, and therefore the nonparametric Kruskal-Wallis test was used for analysis with group as a factor. The $p$ values were corrected for multiple comparisons; a Bonferroni correction factor of 18 and 6 was applied for mRNA and peptides, respectively.

In the absence of significant differences between the five animal groups, as determined by the Kruskal-Wallis test, the groups were combined, and the pooled data were used in analysis of lateralization of the mRNA and peptide levels using Wilcoxon matched pairs signed-rank test. Bonferroni correction factors of nine and three were applied in the RNA and peptide analyses, respectively; adjusted $p$ values are shown. Reported fold changes were defined as ratios between median expression levels. In the replication study the sham-injured $(n=11)$ and UBI ( $n=12$ rats) groups did not differ in expression levels, and were combined for analysis of lateralization; unadjusted $p$ values are shown.

Differences among animal groups in the gene co-expression patterns that characterize regulatory interactions between the genes (Dobrin et al., 2009; Long et al., 2016; Zhang et al., 2020) were assessed by analysis of the coordination strength as well as the proportion of positive and negative gene-gene correlations (Kononenko et al., 2017; 
Zhang et al., 2020). Statistical comparison of the coordination strength between the animal groups was performed using Kruskal-Wallis test to sets of squared values of all Spearman's rank correlation coefficients. Significance of differences in the proportion of positive and negative correlations among animal groups was assessed using the Fisher's exact test with $2 \times 5$ and $2 \times 2$ contingency tables.

In co-expression analysis, intraregional and interregional gene co-expression patterns of the five opioid genes, and those among the five opioid genes and 13 neuroplasticity-related genes (Arc, Bdnf, cFos, Dlg4, Egr1, Homer1, Gap43, GluR1, Grin2a, Grin2b, Nfkbia, Syt4, and Tgfb1) were analyzed. Spearman's rank correlation coefficient was calculated for (1) pairs of the opioid genes for the left and right spinal halves separately $(n=10 /$ each half) and between them $(n=25)$; and (2) pairs of the opioid genes with neuroplasticity-related genes for the left and right spinal halves separately ( $n=65 /$ each half) and between them $(n=130)$. Sample size for each correlation coefficient was $n=10$ animals. The significance level was set to $p \leq 0.05$.

\section{Data availability}

Data supporting the findings of this study are available within the article, its Extended Data, or on request.

\section{Materials}

Naloxone, $\beta$-FNA, NTI, and nor-BNI were purchased from Tocris. All test compounds were dissolved in saline in experiments with HL-PA. Naloxone was dissolved in an infusion buffer in the EMG study.

\section{Results}

To examine whether the UBI effects were mediated through the opioid system, pharmacological approach with the general and selective opioid antagonists was used. The UBI was performed by suction lesion to restrict a damaged area to the hindlimb sensorimotor cortex and examine specific changes in hindlimb motor functions. The HL-PA with contralesional flexion and asymmetry of the NWRs were studied as the readouts of the UBI because they induced or regulated differentially on the left or right body side by opioid peptides; and may be directed along the left-right axis, that is essential for analysis of a side-specific regulation.

\section{Cortical injury sites}

The lesion produced by the UBI was confined to the hindlimb motor area (Zhang et al., 2020). The lesion sites extended $3.2-5.0 \mathrm{~mm}$ rostrocaudally and $1.8-2.8 \mathrm{~mm}$ mediolaterally. The lesion was $1.0-1.5 \mathrm{~mm}$ in depth and did not affect the white matter below the cortex. Because of tissue necrosis around the cavity border, the actual lesion size in some cases was slightly larger than the intended dimensions of $3.5 \times 2 \mathrm{~mm}$. The average lesion volume was $6.05 \pm 1.53 \mathrm{~mm}^{3}$ (mean value $\pm \mathrm{SD}$ ), without accounting for tissue shrinkage because of fixation. The lesion volumes of the cortices from the left $(5.86 \pm 1.86$
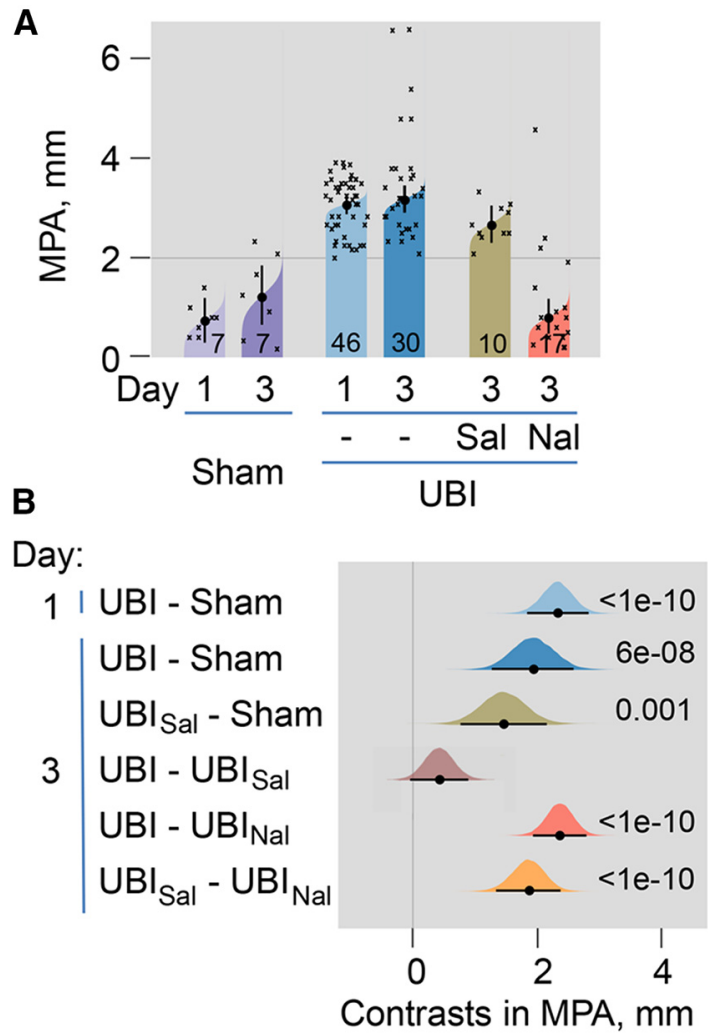

Figure 2. The HL-PA induced by UBI. Effects of the general opioid antagonist naloxone. HL-PA was analyzed in the UBI or sham surgery rats on days 1 and 3 ; and on day 3 in UBI rats 30 min after treatment of with naloxone or saline. The number of rats is shown on the plots (design 2; naloxone: 14 left and 3 right UBI rats; saline: 5 left and 5 right UBI rats). HL-PA was measured in millimeters as the length of the projection of the line connecting symmetric hindlimb distal points on the longitudinal axis of the rat and presented as the MPA. A, The MPA is plotted as median, 95\% HPDCl, and posterior distribution from Bayesian regression. $\boldsymbol{B}$, Contrasts in MPA between rat groups are plotted as medians, 95\% $\mathrm{HPDCl}$ and densities from Bayesian sampler. Adjusted $p$ values are shown if they are $<0.05$ for differences in MPA between rat groups. Differences were considered to be significant if $95 \% \mathrm{HPDCl}$ did not include zero, and adjusted $p$ values were $<0.05$. Time course, comparison of isoflurane and pentobarbital anesthesia, and effects of spinal cord transection and administration of saline or naloxone on HL-PA after the left and right-side UBI are shown on Extended Data Figure 2-1.

$\left.\mathrm{mm}^{3}, n=10\right)$ and right $\left(6.36 \pm 1.22 \mathrm{~mm}^{3}, n=11\right) \mathrm{UBI}$ rats were similar ( $p=0.47$; two tailed $t$ test).

\section{The UBI-induced HL-PA: effects of the general opioid antagonist naloxone}

The UBI induced HL-PA that was manifested as flexion of the contralesional hindlimb (Figs. 1, 2; Extended Data Fig. 2-1). The MPA was substantially ( $\sim 3$-fold $)$ greater after UBI compared with sham surgery (Fig. 2). The MPA of the left and right-side UBI groups did not differ at alltime points analyzed and did not change from day 1 to day 8 after the injury in both groups (Extended Data 


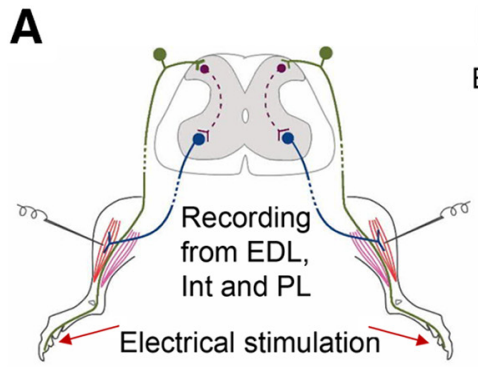

D Naloxone
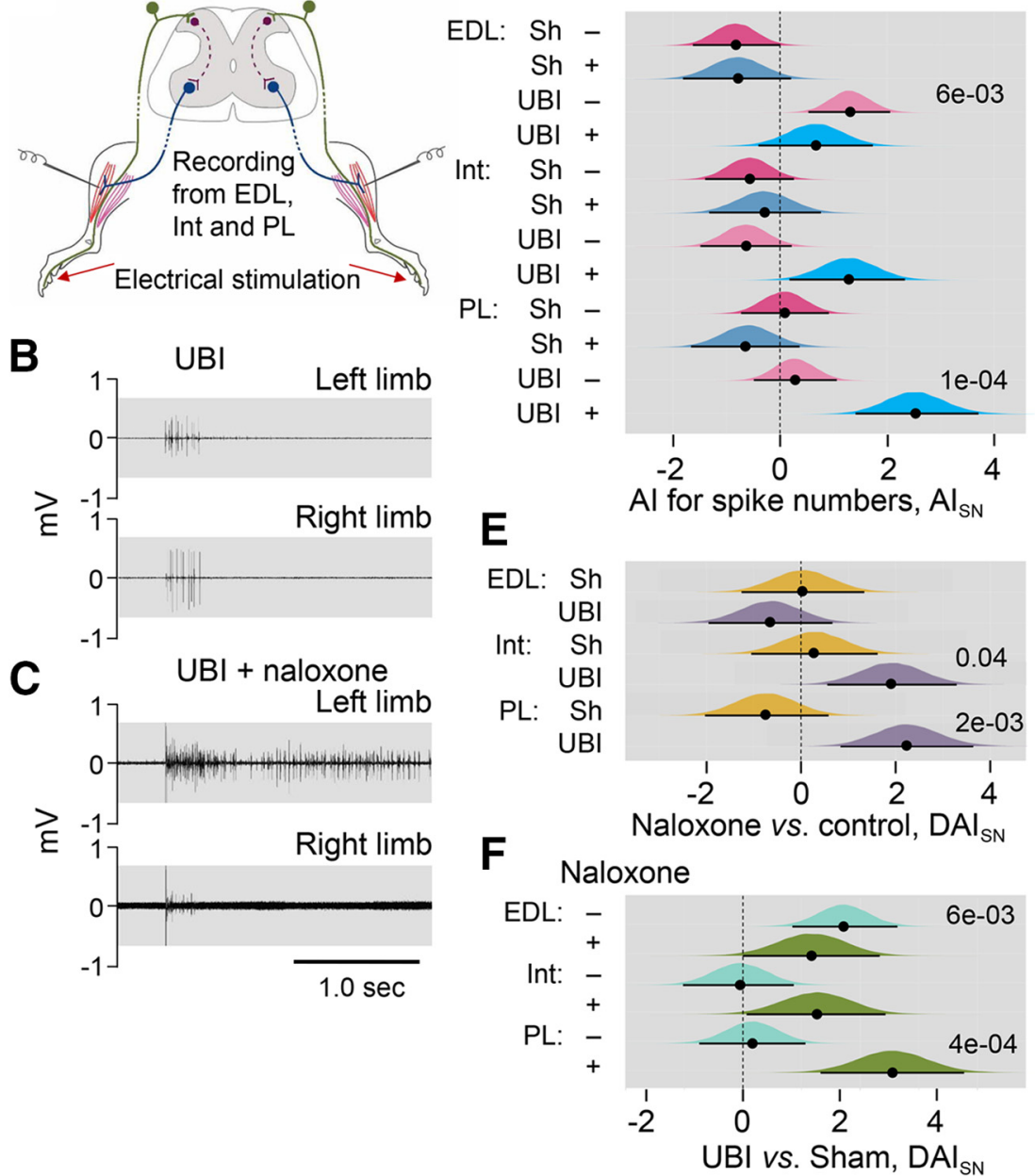

Figure 3. Effects of naloxone on the left-right asymmetry index for the spike number $\left(\mathrm{Al}_{\mathrm{SN}}\right)$ of the EDL, Int, and PL muscles in the $\mathrm{UBI}$ rats. $\boldsymbol{A}$, Experimental design. Rats with the right UBI or right sham surgery (Sh) were exposed to complete spinal cord transection and decerebration, and were infused with naloxone or infusion buffer. The NWRs of the left and right limbs were stimulated and recorded ipsilaterally. EMG activity of left and right hindlimb muscles was evoked by electrical stimulation of symmetrical digits of left and right hindlimbs. Four groups consisted of 39 rats including 11 sham and $14 \mathrm{UBI}$ not treated (control) rats, and seven sham and seven UBI rats treated with naloxone rats were analyzed between third and sixth day after UBI or sham surgery. The number of animals which data were used in statistical analysis is shown in Extended Data Figure 3-1. B, C, Representative EMG responses of the Int muscle to electrical stimulation of digit 4 of the UBI rats. $\boldsymbol{D}$, The left-right asymmetry index for the spike number $\left(\mathrm{Al} \mathrm{INN}_{\mathrm{S}}=\right.$ $\log _{2}\left[\left(1+S N_{\text {Left }}\right) /\left(1+S N_{\text {Right }}\right)\right]$; where Left and Right were values for the left and right side). $\boldsymbol{E}$, Difference between the naloxonetreated and naloxone-untreated (control) groups in $\mathrm{Al}_{\mathrm{SN}}\left[\Delta \mathrm{Al}=\left(\mathrm{Al}_{\text {Naloxone }}-\mathrm{Al}_{\text {Control }}\right)\right]$. $\boldsymbol{F}$, Difference between the UBI and respective sham surgery groups in $\mathrm{Al}_{\mathrm{SN}}\left[\Delta \mathrm{Al}=\left(\mathrm{Al}_{\mathrm{UBI}}-\mathrm{Al}_{\text {sham }}\right)\right]$. Medians, 95\% HPDC intervals and densities of posterior estimates from Bayesian sampler are plotted. Asymmetry and contrast between the groups were defined as significant if $95 \%$ HPDC intervals for $\mathrm{Al}_{\mathrm{SN}}$ did not include zero, and adjusted $p$ values were $<0.05$.

Fig. 2-1A). The MPA was virtually the same under isoflurane and pentobarbital anesthesia (Extended Data Fig. 2$1 D, E)$. After complete spinal cord transection, HL-PA persisted essentially with the same MPA (Extended Data Fig. 2-1F,G), suggesting that neuroplasticity processes induced by $U B I$ in the lumbar neural circuits underlie the HL-PA maintenance.

To examine whether opioid receptors mediate the UBIinduced formation of HL-PA, the effects of the general opioid antagonist naloxone were analyzed (Fig. 2; Extended Data Fig. 2-1H-J). Naloxone or saline was administered to the UBI rats 30 min before the HL-PA analysis
(Fig. 1, design 2) in rats with intact (Fig. 2) and transected (Extended Data Fig. 2-1H-J) spinal cords. In both experiments naloxone injection resulted in substantial ( 3 -fold) decreases in the MPA, suggesting a role of the opioid system in asymmetric spinal processes underlying HL-PA development.

\section{Effect of naloxone on the hindlimb NWRs in the UBI rats}

Along with changes in hindlimb posture, the UBI produced asymmetry in the hindlimb NWRs (Zhang et al., 2020). To reveal a role of the opioid system, we examined 
whether naloxone interferes with the hindlimb NWRs evoked by electrical stimulation of symmetric digits of left and right hindlimbs, and recorded ipsilaterally using EMG techniques in unanesthetized decerebrate UBI rats with transected spinal cord (Fig. 3). The EMG responses of the EDL, Int, and PL muscles were analyzed in four groups of rats that had the right-side UBI or right-side sham surgery, and that were or were not treated with naloxone (Fig. 3; Extended Data Fig. 3-1). Effects of the right side UBI were analyzed because they were substantially greater compared with those induced by the left side lesion (Zhang et al., 2020).

Strict criteria were applied to ensure data comparability between two hindlimbs for (1) the experimental procedures including the symmetry of stimulation and recording conditions and positioning of electrodes; (2) the reflex characteristics by analysis of the asymmetry index; and (3) statistical analysis (described in detail in Materials and Methods). The core criteria were similar with those implemented by Hultborn and Malmsten (1983a,b). To minimize interindividual variations, the asymmetry index calculated for each animal but not the absolute values of the reflex size was analyzed. This analysis allowed double assessment that identified the asymmetric versus symmetric patterns, first, within each of the UBI and control groups, and, second, between the animal groups. Because multiple responses were measured for the same animal, including two of its limbs, three muscles, and the varying stimulation conditions, and because they were analyzed within an animal group and between the groups, we applied mixed-effects models using Bayesian inference.

Asymmetry in EMG responses to current stimulation was compared between the rat groups using the left/right asymmetry index $\left(A l=\log _{2}[L / R]\right.$, were $L$ and $R$ were values for the left and right limb muscles) for the threshold $\left(\mathrm{Al}_{\text {Thr }}\right)$ or the spike number $\left(\mathrm{Al}_{\mathrm{SN}}\right)$. When reflexes on the both sides are equal (i.e., the left/right ratio $=1$ ), the asymmetry index is zero; if reflexes are of double size on the Left or Right side (i.e., the left/right ratio $=2.0$ or 0.5 ) the asymmetry index is +1 or -1 , respectively.

The number of analyzed animals is shown in Extended Data Figure 3-1. There were no differences from zero in the $\mathrm{Al}_{\mathrm{Thr}}$ for the UBI and sham surgery groups, infused with either naloxone or with control solution. Moreover, there were no differences in $\mathrm{Al}_{\mathrm{Thr}}$ among these groups. No asymmetries in the number of evoked spikes ( $\mathrm{Al}_{\mathrm{SN}}$ ) were revealed in the sham surgery rats that were treated with naloxone or control solution, with the exception of EDL that showed a higher number of spikes on the right versus left side in the group infused with control solution with borderline significance (median of the posterior distribution was $-0.83,95 \% \mathrm{HPDCl}=[-1.63,-0.01]$; Fig. $3 D$ ). In the UBI group, significant asymmetry in the number of spikes in rats infused with control solution was identified for the EDL muscle (median $=1.30,95 \% \mathrm{HPDCl}=[0.53$, 2.06], $p=0.006$, the left/right ratio $=2.5$; Fig. $3 D$ ), and in naloxone-treated rats for the $\mathrm{PL}$ (median $=2.52,95 \%$ $\mathrm{HPDCl}=[1.41,3.71], p=1 \mathrm{e}-04$, the left/right ratio $=5.7)$. The Int demonstrated asymmetry in the number of spikes with borderline significance $($ median $=1.28,95 \% \mathrm{HPDCl}=$ $[0.18,2.33]$, the left/right ratio $=2.4)$ in UBI rats.
No effects of naloxone in comparison with respective control (contrast: naloxone vs control) were evident in rats with sham surgery whereas blockade of opioid receptors in the UBI rats resulted in increase in the spike number on the left (contralesional) compared with the right (ipsilesional) side for the Int (median $=1.92,95 \% \mathrm{HPDCl}=[0.56$, 3.29], $p=0.04$, left/right ratio $=3.8$ ) and $\mathrm{PL}$ (median $=2.24$, $95 \% \mathrm{HPDCl}=[0.83,3.64], p=0.01$, difference in the left $/$ right ratio $=4.7$; Fig. $3 E$ ). Representative examples of the UBI-induced asymmetry for the Int muscle are shown on Figure $3 B, C$. The UBI and sham surgery groups treated with naloxone (contrast: UBI versus sham surgery) were different for the PL (median $=3.18,95 \% \mathrm{HPDCl}=[1.66$, 4.72], $p=4 \mathrm{e}-04$, difference in the left/right ratio $=9.1$ ) and for the Int with borderline significance (median $=1.57$, $95 \% \mathrm{HPDCl}=[0.08,3.04]$, difference in the left/right ratio $=3.0$; Fig. $3 F$ ). The contrast between the UBI and sham surgery in the group received control solution, was significant for the EDL (median=2.14, 95\% $\mathrm{HPDCl}=$ $[1.05,3.30], \quad p=0.002$, difference in the left/right ratio $=4.4)$.

In summary, naloxone did not produce noticeable effects on (1) the left-right balance in stimulation thresholds of the three muscles in each $\mathrm{UBI}$ and sham surgery groups, and (2) differences in this balance between these groups. No asymmetry in the spike numbers in sham surgery groups treated with naloxone or control solution was evident. However, naloxone administration to UBI rats produced asymmetric patterns in the NWRs of the PL and Int characterized by a higher activity on the contralesional (left) compared with ipsilesional (right) side. Thus, the UBI effects may be counteracted by the endogenous opioid peptides resulting in maintenance of the symmetric patterns of the PL and Int NWRs. Naloxone by blocking these effects, unmasked the cryptic lateralized changes induced by the UBI.

\section{UBI effects on expression of the opioid genes and their co-expression patterns with neuroplasticity genes in the lumbar spinal cord}

Formation of HL-PA and asymmetry in the NWRs after the UBI may require neuroplastic rearrangements based on changes in expression of opioid and/or neuroplasticity genes in the lumbar spinal cord. It has been demonstrated that the UBI modified the expression of neuroplasticity genes, as well as robustly impaired coordination of their expression within and between the ipsilesional and contralesional halves of the lumbar spinal cord (Zhang et al., 2020). Here, we assessed whether left and right-side UBI affects expression of the five opioid genes [the $\mu$-receptor, $\delta$-receptor, and $\kappa$-receptor genes, Oprm1, Oprd1, and Oprk1, respectively, and the prodynorphin (Pdyn) and proenkephalin (Penk) opioid peptide precursor genes], and their co-expression patters with 13 neuroplasticity genes (Arc, Bdnf, cFos, Dlg4, Egr1, Homer-1, Gap43, GluR1, Grin2a, Grin2b, Nfkbia, Syt4, and Tgfb1) in the lumbar spinal cord. We also examined whether expression of the opioid genes is lateralized in the lumbar spinal cord assuming that the asymmetric expression may be a basis for the left and right side specific opioid effects on 
HL-PA formation after the UBI. The left and right spinal cord may differ in the level of opioid receptor subtypes, in the proportions of these subtypes, in the proportion of the precursor peptide genes giving rise to the endogenous ligands for $\mu$-receptor, $\delta$-receptor, and $\kappa$-receptor. To address these issues, the expression levels and the Oprd1/ Oprm1, Oprk1/Oprd1, and Oprk1/Oprm1 ratio along with the Pdyn/Penk ratio were compared between the left and right spinal halves. We also analyzed the levels of LER and MEAP, Pdyn and Penk markers, respectively, as well as their ratio. Five groups including the left-side and rightside UBI rats, the left and right-side sham surgery rats and intact rats were analyzed.

The Kruskal-Wallis test did not reveal differences among the five animal groups in the levels of opioid mRNAs and of the two opioid peptides, in mRNA ratio for opioid receptors and opioid peptide precursors, as well as for the LER/MEAP ratio. Next, to assess whether the opioid system is lateralized in the lumbar spinal cord, the data for the five groups were combined into the left and right datasets ( $n=50$ rats) and compared using the Wilcoxon matched pairs test. Analysis revealed significantly higher expression levels of the Oprd1 receptor gene (1.19-fold between the medians; $p=1.2 \mathrm{e}-06)$, as well as higher Oprd1/Oprm1 (1.12-fold; $p=0.016$ ) and Pdyn/Penk (1.14-fold; $p=0.045)$ ratios in the left compared with the right spinal cord (Fig. $4 A, F, I)$. In contrast, the Oprk1/Oprd1 ratio (1.14-fold; $p=0.001$ ) was higher on the right spinal side (Fig. 4D).

The same results were obtained in the replication study $(n=23)$. The analyzed group consisted of the sham-injured $(n=11)$ and UBI $(n=12)$ rats taken from another experiment. These subgroups did not differ in expression levels and were pooled for analysis of lateralization. The Wilcoxon matched pairs test showed significantly higher expression of the Oprd1 gene (1.39-fold between the medians; $p=3.0 \mathrm{e}-04)$, and the Oprd1/Oprm1 (1.24-fold; $p=0.001)$ and Pdyn/Penk (1.24-fold; $p=0.019) \mathrm{mRNA}$ ratio in the left compared with the right spinal half (Extended Data Fig. 4-1A,B,D). In opposite, the proportion of the Oprk1 to Oprd1 mRNA was significantly higher on the right versus left side (Extended Data Fig. 4-1C; 1.12fold; $p=0.028$ ).

Analysis of opioid peptides by the Wilcoxon matched pairs test revealed significantly higher levels of LER (1.48fold; $p=0.002)$, and the LER/MEAP ratio $(1.77$-fold; $p=4.4 \mathrm{e}-06$ ) in the left compared with the right spinal half (Fig. $4 J, L)$. The MEAP levels were significantly higher (1.24-fold; $p=0.002$ ) in the right spinal half compared with the left spinal half (Fig. $4 K$ ).

Gene co-expression patterns characterize regulatory interactions within and across tissues (or CNS areas; Dobrin et al., 2009; Long et al., 2016; Zhang et al., 2020). Here, we assessed whether the left and right UBI affect co-expression patterns of the opioid genes in the left and right halves of the lumbar spinal cord, and between them. Furthermore, we analyzed whether the $\mathrm{UBI}$ affects the co-expression patterns of the opioid genes with the neuroplasticity-related genes. We assumed that the opioid system that modulates activity
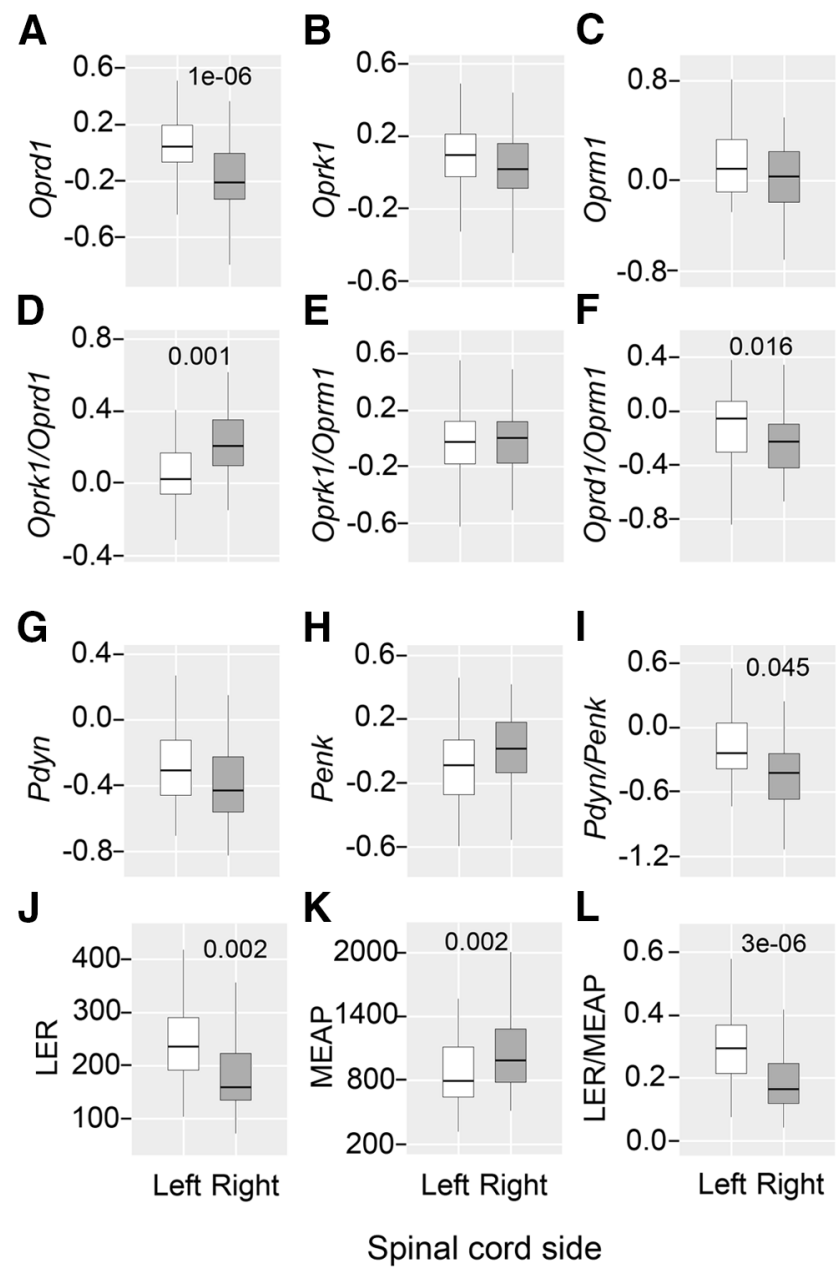

Figure 4. Lateralized expression of the opioid genes and opioid peptides in the lumbar spinal cord. Data for five animal groups were combined separately for each the left and right lumbar spinal halves $(n=50)$, Log $_{2}$-scaled and compared using Wilcoxon matched pairs test. Data are shown for the expression levels of the $\mu$-opioid (Oprm1), $\delta$-opioid (Oprd1), and $\kappa$-opioid (Oprk1) receptor genes; the prodynorphin (Pdyn) and proenkephalin (Penk) opioid peptide precursor genes; and for the Oprk1/ Oprd1, Oprk1/Oprm1, Oprd1/Oprm1, and Pdyn/Penk ratio, along with data for opioid peptides LER and MEAP, the Pdyn and Penk markers, respectively, and for the LER/MEAP ratio. White and dark gray boxes denote the left and right spinal cord. The horizontal line in the box represents the median; the box hinges represent the first (Q1) and third (Q3) quartiles. Upper and lower whiskers extend from the hinge to the highest/lowest value that lies within the 1.5 interquartile range (IQR) of the hinge. The Bonferroni adjusted $p$ values are shown. Analysis of replication sample is shown on Extended Data Figure 4-1.

of neurocircuits and neuroplasticity processes may be co-regulated. Spearman's rank correlations among the expression levels of the five opioid genes; and among the expression levels of the five opioid genes and 13 neuroplasticity-related genes were calculated. The gene-gene coordination strength and the proportion of positive correlations were compared among the naive group, left and right sham groups, and left and right UBI groups. 
Generally, no significant differences in the coordination strength (in other words, in the aggregated level of co-regulation) were observed between animal groups both for the opioid genes and the opioid-vs-neuroplasticity genes. Comparison of the coordination strength did not take into account a sign of correlations, and therefore a separate analysis was performed to assess differences in the proportion of positive and negative correlations between the animal groups. No differences in the proportion of positive intra-area and inter-area correlations for the opioid genes were found between the groups. In contrast, the number of positive intra-area correlations of opioid genes with neuroplasticity-related genes for the right half of the spinal cord was significantly different $\left(p_{\text {unadjusted }}=8.4 \mathrm{e}-05\right)$ between the five animal groups while for the left half was nominally significant $\left(p_{\text {unadjusted }}=0.048\right.$; Fig. 5$)$. In the right spinal cord, the proportion of positive correlations was lower in the left UBI rats versus left sham surgery group ( $p_{\text {unadjusted }}=2.4 \mathrm{e}-04$ ), and in the right UBI rats versus right sham surgery group with nominal significance $\left(p_{\text {unadjusted }}=0.043\right)$.

For individual genes, differences between UBI groups and sham groups were substantial for Pdyn; UBI significantly reduced the proportion of $P d y n$ positive correlations correlations. The effect was more pronounced for the rightside injury $\left(p_{\text {unadjusted }}=3.9 \mathrm{e}-04\right.$; in the analysis correlations were combined for the left and right halves of the spinal cord). Effects of the left-side impact was at the trend level.

No group effect was evident for the proportion of positive correlations at the inter-area comparison. In summary, UBI does not affect the expression of the opioid genes but may induce the opioid system-mediated changes in expression of neuroplasticity-related genes.

\section{Effect of selective opioid antagonists on formation of HL-PA induced by the left and right-side UBI}

In order to identify subtypes of the opioid receptors mediating the UBI effects we analyzed HL-PA after administration of $\mu$-antagonist $\beta$-FNA, $\delta$-antagonist NTI, and $\kappa$-antagonist nor-BNI (Fig. 6). Effects were compared between rats with the left and right-side UBI. nor-BNI and $\beta$-FNA are long acting antagonists that selectively block these receptor subtypes, but require $\sim 24 \mathrm{~h}$ after administration to do so (Horan et al., 1992; Petrillo et al., 2003; Patkar et al., 2013; Rutten et al., 2018). These antagonists were administered to the UBI rats $24 \mathrm{~h}$ before HL-PA analysis (Fig. 1, design 3). NTI was injected 30 min before the HL-PA analysis (Fig. 1, design 2).

In the left-side UBI group, no substantial effects of $\beta$-FNA and nor-BNI were evident while a marked ( 2fold) decrease in the MPA was induced by NTI (Fig. $6 A, B$ ). In contrast, administration of $\beta$-FNA and nor-BNI, but not $\mathrm{NTI}$, resulted in substantial MPA reduction ( $\sim 2$-fold) in the right-side UBI group (Fig. $6 A, B$ ). Strikingly, effects of NTI and $\beta$-FNA were different between the left and right side UBI groups (Fig. $6 C$ ). Thus, $\beta$-FNA and nor-BNI inhibited formation of the left hindlimb flexion, whereas NTI, in contrast, inhibited formation of the right hindlimb flexion suggesting that effects of the right UBI are mediated through $\mu$-receptors and $\kappa$-receptors, while those of the left UBI by $\delta$-receptors.

\section{Discussion}

The findings of this study were that the general opioid antagonist naloxone and the selective antagonists of opioid receptors blocked the UBI-induced formation of HL-PA. Furthermore, naloxone administration revealed the cryptic contra-ipsilesional asymmetry in NWR induced by the UBI in the PL and Int muscles. We also found that the opioid gene expression and opioid peptides were lateralized in the lumbar spinal cord, and that coordination of the opioid and neuroplasticity-related gene expression was dysregulated after the UBI.

The selective opioid antagonists had differing effects, depending on which side of the brain had the UBI, that was the striking finding (Fig. $7 A, B$ ). The $\mu$-antagonist $\beta$-FNA and $\kappa$-antagonist nor-BNI, reduced the magnitude of the asymmetry after the right but not left UBI. In contrast, the $\delta$-antagonist NTI inhibited HL-PA induced by the left-side but not right-side brain injury. These findings are consistent with the observations that opioid peptides and synthetic opioids may induce HL-PA in rats and cats with intact brain, and that the flexion side is determined by the agonist administered (Fig. 7C; Bakalkin et al., 1980; Chazov et al., 1981; Bakalkin and Kobylyansky, 1989; Pilyavskii et al., 2013; Watanabe et al., 2020). The left hindlimb was flexed after administration of the $\mu$-/ $\delta$-agonist Met-enkephalin, and the selective $\kappa$-agonists dynorphin and U-50488 (Bakalkin et al., 1980; Chazov et al., 1981; Bakalkin and Kobylyansky, 1989; Watanabe et al., 2020). Conversely, Leu-enkephalin, which acts via the $\delta$-receptor, caused the right hindlimb flexion (Bakalkin et al., 1980; Chazov et al., 1981). Together, the antagonist and agonist data suggest that the right side $\mathrm{UBI}$-induced formation of the left flexion is mediated by the $\mu$-receptor and $\kappa$-receptor targeted by endogenous Met-enkephalin and dynorphins, respectively. Complementarily, development of HL-PA with right flexion induced by the left UBI may be mediated by $\delta$-receptor targeted by Leu-enkephalin (Fig. 7).

These findings corroborate the recent observations that selective opioid antagonists modulate the effects of the controlled cortical impact, a model of clinical focal TBI (Watanabe et al., 2020). Similar to the present study, administration of naloxone and $\beta$-FNA but not NTI blocked HL-PA induced by the unilateral right-sided TBI. However, the $\kappa$-antagonists nor-BNI and LY2444296 did not affect the magnitude of the asymmetry after the right side TBI, while the side of flexion occurred was reversed. Instead of contralesional (left) hindlimb flexion the ipsilesional (right) limb was flexed (Watanabe et al., 2020). Thus, $\kappa$-antagonists differently interfered with the effects of the right-side $\mathrm{TBI}$ and the right-side UBI. The UBI and the TBI also differed in the sidedness of their effects on hindlimb posture (Bakalkin et al., 2021). The effects of the left and right UBI were mirror symmetric. In contrast, both the left and right side TBI induced flexion of the left limb. The differences between the injury models may be because of differences in their pathophysiological mechanisms. While UBI effects 
$\begin{array}{llll}\text { Correlation } & -1 & 0 & 1 \\ \text { coefficient, } \rho & & & \end{array}$
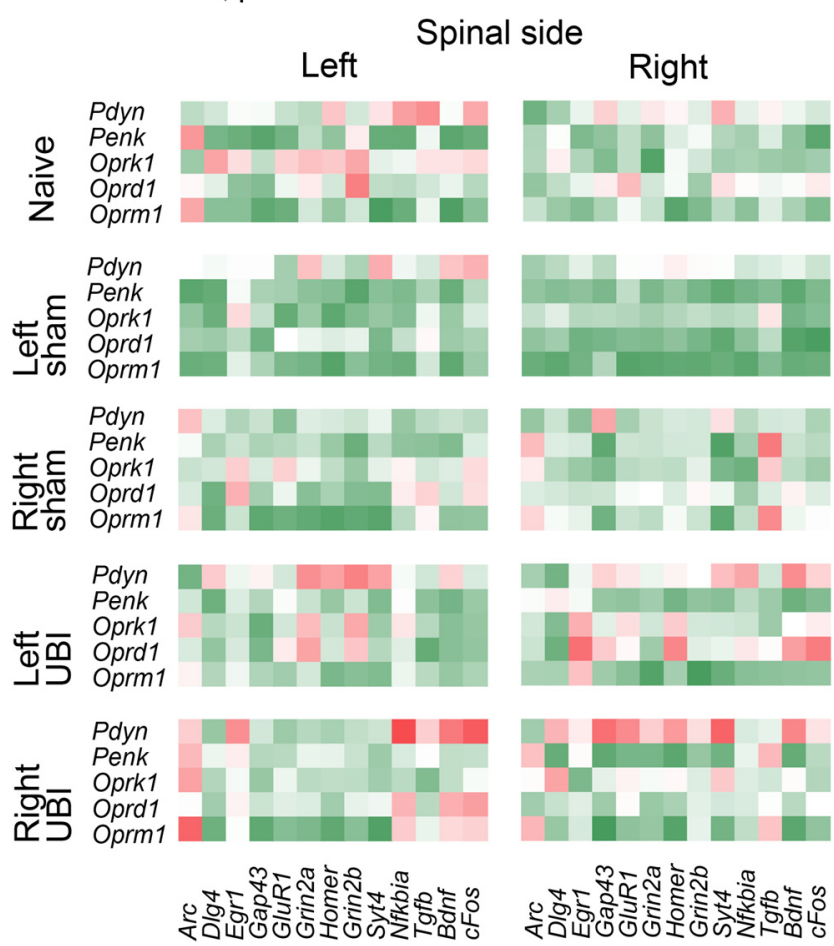

Figure 5. Effects of UBI on intra-area correlations between the opioid and neuroplasticity-related genes (genes analyzed are shown in Extended Data Fig. 5-1) in the left and right halves of the spinal cord. Heatmap for intra-area Spearman's rank correlations between expression levels of five opioid system genes and 13 neuroplasticity-related genes in the left and right spinal cord for the naive group, the left and right sham surgery groups, and left and right UBI groups (five groups; $n=10$ rats/group). Significance of differences in the proportion of positive and negative correlations among five groups, and, separately between two animal groups, were assessed by the Fisher's exact test with $2 \times 5$ or $2 \times 2$ contingency tables, respectively. Twotailed uncorrected $p$ value is shown. Differences among five animal groups for the left and right spinal halves: $p=0.048$ and $p=8.4 \mathrm{e}-05$, respectively. Differences for the right spinal half between the left UBI versus left sham surgery: $p=2.4 \mathrm{e}-04$; and between the right UBI versus right sham surgery: $p=0.043$.

are more local and confined to the hindlimb sensorimotor area, the TBI in addition to the cortical areas also damages the white matter and underlying structures (Hall et al., 2005, 2008; $\mathrm{Ng}$ and Lee, 2019; Lacalle-Aurioles et al., 2020). The TBI effects are caused by mechanical stressinduced axonal and vascular injuries followed by neuronal degeneration and excitotoxicity. These effects are mediated by regulatory molecules that may be similarly activated by the left and right TBI. Some of these molecules may be involved in lateralized processes and produce side specific effects because of lateralization of their target receptors. Thus, the opioid peptides dynorphins are affected by both the left or right side injury (Hauser et al., 2005; Hussain et al., 2012; Kononenko et al., 2018), and may induce a side-specific response, i.e., flexion of the left hindlimb (Bakalkin and Kobylyansky, 1989; Watanabe et al.,
2020). Inhibition of this response by $\kappa$-antagonists could reverse the flexion side if other neurohormones that induce a response on the other (right) side are also activated by the TBI (Watanabe et al., 2020). In contrast to this mechanism, the more local UBI may primarily affect the left or right sided neuronal circuits of the mirror-symmetric neural pathways that convey signals from the injured hemisphere to lumbar motoneurons. These pathways may be locally controlled at different levels of the neuraxis by the lateralized opioid system, and their targeting by selective opioid antagonists may lead to activation or inactivation of their left or right-sided lumbar neurocircuits.

The HL-PA and NWRs were used as the UBI readouts because the opioid system has a role in their formation and regulation, and because they are directed along the mediolateral axis allowing analysis of left-right sided processes. The HL-PA with contralesional flexion is a proxy for hindlimb responses to a unilateral brain lesion and is developed both in animals under anesthesia and un-anesthetized decerebrate animals (Watanabe et al., 2020; Zhang et al., 2020). Previous studies established that the stretch and postural limb reflexes were substantially inhibited by anesthesia (Zhou et al., 1998; Fuchigami et al., 2011) and abolished by spinal cord transection (Miller et al., 1996; Musienko et al., 2010; Frigon et al., 2011). In HL-PA studies, no nociceptive stimulation was applied and tactile stimulation was negligible (DiGiorgio, 1929; Chamberlain et al., 1963; Zhang et al., 2020). Thus, the nociceptive withdrawal and stretch reflexes likely did not contribute to HL-PA formation in the UBI rats that were examined under anesthesia both before and after spinal transection.

The polysynaptic NWRs may undergo pathologic changes after brain injury because of the aberrant activity or injury of descending pathways that converge with inputs from peripheral afferents (Crenna and Frigo, 1984; Duysens et al., 1990, 1992; Rossi and Decchi, 1994; Andersen et al., 1995; Spaich et al., 2004, 2006; Sandrini et al., 2005; Emborg et al., 2009). Asymmetrically exacerbated withdrawal reflexes develop often and lead to flexor spasms in patients after stroke and TBI (Dewald et al., 1999; Serrao et al., 2012; Spaich et al., 2014). The NWRrelated EMG kinematic responses were increased and NWR modulation impaired in patients with hemiparesis (Serrao et al., 2012; Alvisi et al., 2018). UBI produced asymmetric patterns of the NWR of the EDL muscle with higher activity on the contralesional versus ipsilesional side (Zhang et al., 2020), while the Int and PL reflexes were still symmetric after the injury. However, blockade of opioid receptors by naloxone revealed a marked asymmetry of the NWR of these two muscles with higher ( 4fold) responses on the contralesional versus ipsilesional side. Thus, the UBI effects were cryptic; the opioid system likely counteracted the UBI-induced maladaptive changes through inhibition of the contralesional and/or activation of ipsilesional NWRs that resulted in maintenance of the symmetric NWR patterns. In animals with sham surgery, the opioid system probably was not involved in coordination of the contra-ipsilesional balance of the PL, Int, and EDL NWRs. 
A

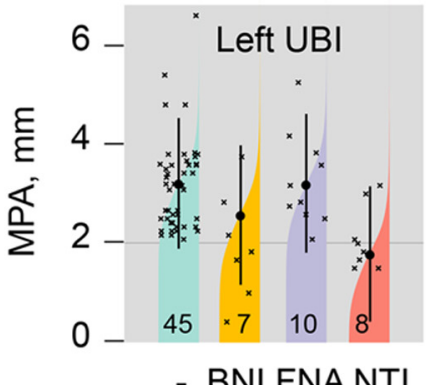

B

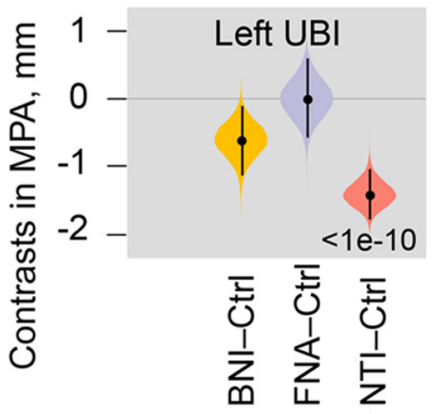

C

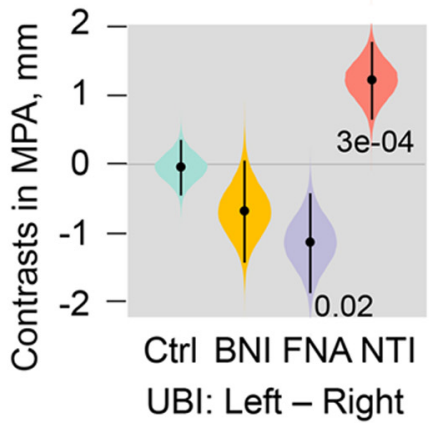

Figure 6. Effects of nor-BNI, $\beta-F N A$, and NTI, the selective $\kappa$-opioid, $\mu$-opioid, and $\delta$-opioid antagonists, respectively, on HL-PA induced by the left and right UBI. The UBI rats were treated with nor-BNI (BNI) or $\beta$-FNA (FNA) $1 \mathrm{~d}$ before (design 3), or with NTI 30 min before (design 2) HL-PA analysis. $\boldsymbol{A}$, The MPA is plotted as median, $95 \% \mathrm{HPDCl}$, and posterior distribution from Bayesian regression. The number of rats is shown on the plot. $\boldsymbol{B}$, Contrasts in MPA between a rat group treated with a given antagonist and respective saline group (Ctrl). $\boldsymbol{C}$, Contrasts in MPA between rat groups with the left or right-side $\mathrm{UBI}$; the UBI rats in each pair of groups were treated with the same antagonist or saline (Ctrl). Contrasts are plotted as medians, 95\% HPDCl and densities from Bayesian sampler. Adjusted $p$ values are shown if they are $<0.05$ for differences in MPA between the groups. Differences were considered to be significant if $95 \% \mathrm{HPDCl}$ did not include zero, and adjusted $p$ values were $<0.05$.

Naloxone effects were evident in the UBI animals with transected spinal cord suggesting that asymmetric hindlimb posture and reflexes are controlled by spinal neural circuits regulated by the endogenous opioid peptides. In the spinal cord, the $\mu$-opioid, $\delta$-opioid, and $\kappa$-opioid receptors are expressed both in the dorsal and ventral horns (Kononenko et al., 2017; Wang et al., 2018). The $\delta$-opioid receptor is expressed in multiple classes of neurons that regulate spinal motor control while the $\delta$-receptors and $\mu$-receptors are co-expressed in V1 ventral horn interneurons (Wang et al., 2018). Opioid agonists exert their action on ventral root reflexes via presynaptic inhibition of afferent signaling, postsynaptic inhibition of the dorsal horn interneurons and actions on ventral horn interneurons regulating motoneurons activity (Wang et al., 2018). This may result in suppression of the ipsilateral reflexes (Faber et al., 1997) while targeting of opioid receptors in neurons surrounding the central canal (Mansour et al., 1994; Wang et al., 2018) may inhibit the spinal commissural pathways (Light and Perl, 1979; Petkó et al., 2004) and contralateral reflexes (Duarte et al., 2019). Opioid peptides suppressed reflexes evoked by electrical stimulation of the skin (Clarke et al., 1992; Steffens and Schomburg, 2011) that may attenuate pain and to promote healing (Steffens and Schomburg, 2011). Spinal circuits that mediate the asymmetric UBI effects may be controlled by the same opioid mechanisms.

The side-specific opioid effects suggest that the opioid receptor subtypes are lateralized in the spinal cord, and that the asymmetrically distributed receptors differentially regulate the mirror-symmetric spinal neural circuits that control the left and right hindlimb muscles. Asymmetric expression of the opioid genes was earlier reported for the cervical spinal cord (Kononenko et al., 2017). All three opioid receptors were lateralized to the left while their proportions were different between the left and right spinal halves. The expression profiles were coordinated between the dorsal and ventral domains but differently on the left and right sides. The present study identified generally the same lateralization patterns in the lumbar spinal cord (Fig. 7D,E). Expression of the $\delta$-receptors was lateralized to the left whereas a proportion of $\kappa$-receptors and $\delta$-receptors (the Oprk1/Oprd1 expression ratio) was higher on the right side. Opioid peptides were also lateralized. The levels of LER (a prodynorphin marker), and the LER to MEAP (a proenkephalin marker) ratio, and, consistently, the ratio of prodynorphin to proenkephalin mRNA were greater in the left half compared with the right half. MEAP was lateralized to the right. Lateralization of the opioid system in the spinal cord may provide a molecular basis for differential regulation of the UBI-induced left and right sided processes.

The previous study demonstrated that the UBI robustly impaired coordination of expression of neuroplasticity-related genes within and between the ipsilesional and contralesional halves of the lumbar spinal cord (Zhang et al., 2020). Among these genes, expression of the Grin2a, $D / g 4$, and Tgfb1 genes associated with the glutamate system was affected. The Grin2a subunit of the glutamate receptors regulates formation and plasticity of neural circuits. The Dlg4 gene gives rise to PSD95 involved in post-NMDA receptor activation events (Won et al., 2016). Tgfb 1 codes for transforming growth factor $\beta 1$ regulating glutamate neurotoxicity (Buisson et al., 2003; Santibañez et al., 2011). The present study did not reveal UBI-induced changes in the expression of the opioid genes. However, their co-expression pattern with neuroplasticity-related genes was dysregulated as evident from the decrease in the proportion of positive gene-gene correlations after the UBI. The decrease was robust in the right 


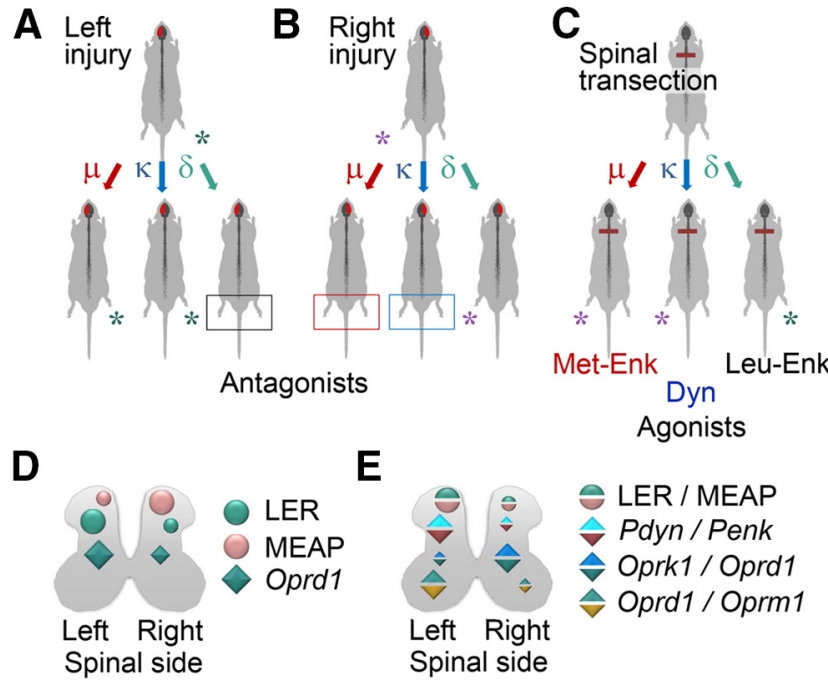

Figure 7. The left and right side-specific effects of opioid antagonists and agonists and the underlying lateralization of the opioid system. $\boldsymbol{A}, \boldsymbol{B}$, Effects of selective $\mu$-opioid $(\beta$-FNA), $\kappa$-opioid (nor-BNI), and $\delta$-opioid (NTI) antagonists on HL-PA induced by the left or right side UBI. $\boldsymbol{C}$, Development of HL-PA with the left or right hindlimb flexion induced by the preferential endogenous $\mu$-agonist Met-enkephalin (Met-Enk), $\kappa$-agonist dynorphin (Dyn), and $\delta$-agonist Leu-enkephalin (Leu-Enk; data from Bakalkin et al., 1980; Chazov et al., 1981; Bakalkin and Kobylyansky, 1989). D, Lateralization of opioid peptides LER, the Pdyn marker, and MEAP, the Penk marker, and the lateralized expression of the $\delta$-opioid receptor in the lumbar spinal cord. $\boldsymbol{E}$, Differences in ratio of (1) LER and MEAP; (2) mRNA levels of their precursor proteins (Pdyn/Penk), respectively; (3) mRNA levels of $\kappa$-opioid and $\delta$-opioid receptors (Oprk1/Oprd1); and (4) mRNA levels of $\delta$-opioid and $\mu$-opioid receptors (Oprd1/ Oprm1). The findings suggest that the mirror symmetric neural circuits mediating effects of the left and right brain injury on the contralesional hindlimb responses are differentially regulated by the lateralized opioid system.

half of the spinal cord especially after the left UBI. Changes in coordination of the opioid-neuroplasticity-related gene expression is a novel phenomenon suggesting that the UBI effects on neuroplastic processes are mediated by the opioid system.

The side-specific antagonist effects on HL-PA were revealed in anaesthetized animals that limited the understanding of biological and clinical role of this phenomenon. Electrophysiological mechanisms of the HL-PA formation and clinical correlates of this asymmetry have not been yet addressed. Nonetheless, the HL-PA exhibits several features of the human upper motor neuron syndrome induced by TBI or stroke. First, they include the asymmetric pattern with deficits on the contralesional side. Second, formation of contralesional flexion correlates with the asymmetric hindlimb motor impairments in locomotor tasks (Lukoyanov N, Bakalkin G, unpublished observations). Third, HL-PA may depend on the efferent drive but not on the afferent stimulation because it is resistant to bilateral lumbar deafferentation (Zhang et al., 2020). In this feature, HL-PA is similar with "spastic dystonia," a tonic muscle overactivity that contributes to "hemiplegic posture" in patients (Gracies, 2005; Sheean and McGuire,
2009; Lorentzen et al., 2018). Another limitation is that the pathways from the injured brain to the spinal motor circuits that are targeted by opioid antagonists have not been identified. These clinical and mechanistic issues are beyond the scope of this report on the bipartite neurohormonal regulation, and should be addressed in further studies.

Functional specialization of the left and right hemispheres is an organizing principle of the brain (MacNeilage et al., 2009; Concha et al., 2012; Duboc et al., 2015; Güntürkün et al., 2020; Vallortigara and Rogers, 2020). The computational advantages of the specialization may include paralleled processing of information modules in the left and right hemispheres that increases the flow of information, and improves functional performance. Lasting regulation of the lateralized processes may be accomplished by local paracrine molecules, including neuropeptides, that may preferentially operate either on the left or right side of the midline (Zink et al., 2011; Hussain et al., 2012; Marlin et al., 2015; Watanabe et al., 2015, 2020; Kononenko et al., 2017, 2018; Nation et al., 2018; Phelps et al., 2019). Our findings suggest a more general role for the lateralized neuropeptide systems than regulation of the lateralized functions. We hypothesize that the I eft-side and right-side specific neurohormonal mechanism regulate the non-lateralized, mirror-symmetric neural circuits that control paired organs and extremities including the left and right hindlimbs. Neuropeptides may differentially target the left and right counterparts of these circuits and, in this way, control left-right balance in their functional performance. This bipartite mechanism may be based on lateralization of the neurohormonal systems, and may operate locally (e.g., within the lumbar spinal cord), or at the several levels of the neuraxis by controlling neural pathways that convey signals from the left and right hemispheres to the contralateral hindlimb motoneurons. A unilateral brain lesion may shift this balance to the left or to the right, depending on the side of injury, that impairs the left-right side specific neurohormonal control leading to asymmetric functional deficits.

In conclusion, this study presents evidence for the opioid neurohormonal mechanism that may mediate effects of a UBI on spinal motor circuits and determine whether the left or right hindlimb is affected. This mechanism was revealed by analysis of selective opioid antagonists which effects were found to be specific for the injury side. These findings corroborate the observations that the endogenous opioid peptides and selective synthetic agonists of opioid receptors may mimic the effects of unilateral brain lesion by producing the left and right hindlimb postural responses in animals with intact brains (Bakalkin et al., 1980, 1986; Chazov et al., 1981; Bakalkin and Kobylyansky, 1989; Watanabe et al., 2020). This mechanism may rely on the lateralized opioid receptors and opioid peptides in the lumbar spinal cord, and on coordination of expression of the opioid and neuroplasticityrelated genes. Together these findings suggest that mirror-symmetric neural circuits that mediate the effects of left and right brain injury on the contralesional hindlimbs are differentially controlled by the lateralized opioid system.

Several experimental and clinical studies demonstrated that the general opioid antagonists naloxone and naltrexone may decrease spasticity caused by progressive 
multiple sclerosis (Gironi et al., 2008) and lessen neurologic deficits developed after cerebral ischemia (Baskin and Hosobuchi, 1981; Hosobuchi et al., 1982; Baskin et al., 1984, 1994; Jabaily and Davis, 1984; Namba et al., 1986; Skarphedinsson et al., 1989; Hans et al., 1992; Wang et al., 2019). It is important to identify clinical and pathophysiological features of sensorimotor impairments and postural deficits that are mediated by the opioid receptor subtypes, and to establish whether pharmacological targeting of these features may contribute to sensorimotor recovery and compensate for postural deficits after TBI and stroke. From a biological standpoint, it is interesting to ascertain whether the neurohormonal mechanisms may serve to control a balance between the left-right processes in bilaterally symmetric animals.

\section{References}

Adkins DL, Boychuk J, Remple MS, Kleim JA (2006) Motor training induces experience-specific patterns of plasticity across motor cortex and spinal cord. J Appl Physiol 101:1776-1782.

Alvisi E, Serrao M, Conte C, Alfonsi E, Tassorelli C, Prunetti P, Cristina S, Perrotta A, Pierelli F, Sandrini G (2018) Botulinum toxin A modifies nociceptive withdrawal reflex in subacute stroke patients. Brain Behav 8:e01162.

Andersen OK, Jensen LM, Brennum J, Arendt-Nielsen L (1995) Modulation of the human nociceptive reflex by cyclic movements. Eur J Appl Physiol Occup Physiol 70:311-321.

Anderson MF, Winterson BJ (1995) Properties of peripherally induced persistent hindlimb flexion in rat: involvement of $\mathrm{N}$-methylD-aspartate receptors and capsaicin-sensitive afferents. Brain Res 678:140-150.

Bakalkin G, Kobylyansky AG (1989) Opioids induce postural asymmetry in spinal rat: the side of the flexed limb depends upon the type of opioid agonist. Brain Res 480:277-289.

Bakalkin G, larygin KN, Trushina ED, Titov MI, Smirnov VN (1980) [Preferential development of flexion of the left or right hindlimb as a result of treatment with methionine-enkephalin or leucine-enkephalin, respectively]. Dokl Akad Nauk SSSR 252:762-765.

Bakalkin G, Kobylyansky AG, Nagornaya LV, Yarygin KN, Titov MI (1986) Met-enkephalin-induced release into the blood of a factor causing postural asymmetry. Peptides 7:551-556.

Bakalkin G, Nosova O, Sarkisyan D, Hallberg M, Zhang M, Schouenborg, Marklund N, Watanabe H (2021) Unilateral traumatic brain injury of the left and right hemisphere produces the left hindlimb response in rats. Exp Brain Res, in press.

Baskin DS, Hosobuchi Y (1981) Naloxone reversal of ischaemic neurological deficits in man. Lancet 2:272-275.

Baskin DS, Kieck CF, Hosobuchi Y (1984) Naloxone reversal and morphine exacerbation of neurologic deficits secondary to focal cerebral ischemia in baboons. Brain Res 290:289-296.

Baskin DS, Widmayer MA, Browning JL, Heizer ML, Schmidt WK (1994) Evaluation of delayed treatment of focal cerebral ischemia with three selective kappa-opioid agonists in cats. Stroke 25:2047-2053; discussion 2054.

Buisson A, Lesne S, Docagne F, Ali C, Nicole O, MacKenzie ET, Vivien D (2003) Transforming growth factor-beta and ischemic brain injury. Cell Mol Neurobiol 23:539-550.

Burkner PC (2017) brms: an R package for Bayesian multilevel models using stan. Stat Softw 80:1-28.

Bustin SA, Benes V, Garson JA, Hellemans J, Huggett J, Kubista M, Mueller R, Nolan T, Pfaffl MW, Shipley GL, Vandesompele J, Wittwer CT (2009) The MIQE guidelines: minimum information for publication of quantitative real-time PCR experiments. Clin Chem 55:611-622.
Caeyenberghs K, Leemans A (2014) Hemispheric lateralization of topological organization in structural brain networks. Hum Brain Mapp 35:4944-4957.

Carpenter B, Gelman A, Hoffman MD, Lee D, Goodrich B, Betancourt M, Brubaker M, Guo J, Li P, Riddell A (2017) Stan: a probabilistic programming language. Stat Softw 76:1-31.

Chamberlain TJ, Halick P, Gerard RW (1963) Fixation of experience in the rat spinal cord. J Neurophysiol 26:662-673.

Chazov El, Bakalkin GYa, Yarigin KN, Trushina ED, Titov MI, Smirnov VN (1981) Enkephalins induce asymmetrical effects on posture in the rat. Experientia 37:887-889.

Christensson-Nylander I, Nyberg F, Ragnarsson U, Terenius L (1985) A general procedure for analysis of proenkephalin $B$ derived opioid peptides. Regul Peptid 11:65-76.

Clarke RW, Galloway FJ, Harris J, Taylor JS, Ford TW (1992) Opioidergic inhibition of flexor and extensor reflexes in the rabbit. J Physiol 449:493-501.

Concha ML, Bianco IH, Wilson SW (2012) Encoding asymmetry within neural circuits. Nat Rev Neurosci 13:832-843.

Craig AD (2005) Forebrain emotional asymmetry: a neuroanatomical basis? Trends Cogn Sci 9:566-571.

Crenna P, Frigo C (1984) Evidence of phase-dependent nociceptive reflexes during locomotion in man. Exp Neurol 85:336-345.

Deliagina TG, Orlovsky GN, Selverston AI, Arshavsky YI (2000) Asymmetrical effect of GABA on the postural orientation in Clione. J Neurophysiol 84:1673-1676.

Dewald JP, Beer RF, Given JD, McGuire JR, Rymer WZ (1999) Reorganization of flexion reflexes in the upper extremity of hemiparetic subjects. Muscle Nerve 22:1209-1221.

DiGiorgio AM (1929) Persistence of postural and motor asymmetries of cerebellar origin in spinal animals: I, II, III. Arch Fisiol 27:518580.

Dobrin R, Zhu J, Molony C, Argman C, Parrish ML, Carlson S, Allan MF, Pomp D, Schadt EE (2009) Multi-tissue coexpression networks reveal unexpected subnetworks associated with disease. Genome Biol 10:R55.

Dobson KL, Harris J (2012) A detailed surgical method for mechanical decerebration of the rat. Exp Physiol 97:693-698.

Dolan S, Hastie P, Crossan C, Nolan AM (2011) Co-induction of cyclooxygenase-2 [correction of cyclooxyenase-2] and early growth response gene (Egr-1) in spinal cord in a clinical model of persistent inflammation and hyperalgesia. Mol Pain 7:91.

Duarte J, Fernandes EC, Kononenko O, Sarkisyan D, Luz LL, Bakalkin G, Safronov BV (2019) Differential suppression of the ipsi- and contralateral nociceptive reflexes in the neonatal rat spinal cord by agonists of $\mu-, \delta$ - and $\kappa$-opioid receptors. Brain Res 1717:182-189.

Duboc V, Dufourcq P, Blader P, Roussigné M (2015) Asymmetry of the brain: development and implications. Annu Rev Genet 49:647672.

Duysens J, Trippel M, Horstmann GA, Dietz V (1990) Gating and reversal of reflexes in ankle muscles during human walking. Exp Brain Res 82:351-358.

Duysens J, Tax AA, Trippel M, Dietz V (1992) Phase-dependent reversal of reflexly induced movements during human gait. Exp Brain Res 90:404-414.

Emborg J, Spaich EG, Andersen OK (2009) Withdrawal reflexes examined during human gait by ground reaction forces: site and gait phase dependency. Med Biol Eng Comput 47:29-39.

Epstein I, Finkbeiner S (2018) The Arc of cognition: signaling cascades regulating Arc and implications for cognitive function and disease. Semin Cell Dev Biol 77:63-72.

Faber ES, Chambers JP, Brugger F, Evans RH (1997) Depression of $A$ and $C$ fibre-evoked segmental reflexes by morphine and clonidine in the in vitro spinal cord of the neonatal rat. $\mathrm{Br} \mathrm{J}$ Pharmacol 120:1390-1396.

Frigon A, Johnson MD, Heckman CJ (2011) Altered activation patterns by triceps surae stretch reflex pathways in acute and chronic spinal cord injury. J Neurophysiol 106:1669-1678. 
Fuchigami T, Kakinohana O, Hefferan MP, Lukacova N, Marsala S, Platoshyn O, Sugahara K, Yaksh TL, Marsala M (2011) Potent suppression of stretch reflex activity after systemic or spinal delivery of tizanidine in rats with spinal ischemia-induced chronic spastic paraplegia. Neuroscience 194:160-169.

Fujibayashi K, Kubota K, Saito K (1998) Effects of R-84760, a selective kappa-opioid receptor agonist, on nociceptive reflex in isolated neonatal rat spinal cord. Eur J Pharmacol 343:171-177.

Gelman A (2019) Prior choice recommendations. In: Stan-dev/stan. GitHub.

Gironi M, Martinelli-Boneschi F, Sacerdote P, Solaro C, Zaffaroni M, Cavarretta R, Moiola L, Bucello S, Radaelli M, Pilato V, Rodegher M, Cursi M, Franchi S, Martinelli V, Nemni R, Comi G, Martino G (2008) A pilot trial of low-dose naltrexone in primary progressive multiple sclerosis. Mult Scler 14:1076-1083.

Gotts SJ, Jo HJ, Wallace GL, Saad ZS, Cox RW, Martin A (2013) Two distinct forms of functional lateralization in the human brain. Proc Natl Acad Sci USA 110:E3435-E3444.

Gracies JM (2005) Pathophysiology of spastic paresis. I: paresis and soft tissue changes. Muscle Nerve 31:535-551.

Grasselli G, Strata P (2013) Structural plasticity of climbing fibers and the growth-associated protein GAP-43. Front Neural Circuits 7:25.

Güntürkün O, Ocklenburg S (2017) Ontogenesis of lateralization. Neuron 94:249-263.

Güntürkün O, Ströckens F, Ocklenburg S (2020) Brain lateralization: a comparative perspective. Physiol Rev 100:1019-1063.

Hall ED, Sullivan PG, Gibson TR, Pavel KM, Thompson BM, Scheff SW (2005) Spatial and temporal characteristics of neurodegeneration after controlled cortical impact in mice: more than a focal brain injury. J Neurotrauma 22:252-265.

Hall ED, Bryant YD, Cho W, Sullivan PG (2008) Evolution of posttraumatic neurodegeneration after controlled cortical impact traumatic brain injury in mice and rats as assessed by the de Olmos silver and fluorojade staining methods. J Neurotrauma 25:235-247.

Hans P, Brichant JF, Longerstay E, Damas F, Remacle JM (1992) Reversal of neurological deficit with naloxone: an additional report. Intensive Care Med 18:362-363.

Harris KP, Zhang YV, Piccioli ZD, Perrimon N, Littleton JT (2016) The postsynaptic t-SNARE Syntaxin 4 controls traffic of Neuroligin 1 and Synaptotagmin 4 to regulate retrograde signaling. Elife 5: e13881.

Hauser KF, Aldrich JV, Anderson KJ, Bakalkin G, Christie MJ, Hall ED, Knapp PE, Scheff SW, Singh IN, Vissel B, Woods AS, Yakovleva T, Shippenberg TS (2005) Pathobiology of dynorphins in trauma and disease. Front Biosci 10:216-235.

Hayashi M, Ueyama T, Nemoto K, Tamaki T, Senba E (2000) Sequential mRNA expression for immediate early genes, cytokines, and neurotrophins in spinal cord injury. J Neurotrauma 17:203-218.

Horan P, Taylor J, Yamamura HI, Porreca F (1992) Extremely longlasting antagonistic actions of nor-binaltorphimine (nor-BNI) in the mouse tail-flick test. J Pharmacol Exp Ther 260:1237-1243.

Horstick EJ, Bayleyen Y, Burgess HA (2020) Molecular and cellular determinants of motor asymmetry in zebrafish. Nat Commun 11:1170.

Hosobuchi Y, Baskin DS, Woo SK (1982) Reversal of induced ischemic neurologic deficit in gerbils by the opiate antagonist naloxone. Science 215:69-71.

Hultborn H, Malmsten J (1983a) Changes in segmental reflexes following chronic spinal cord hemisection in the cat. I. Increased monosynaptic and polysynaptic ventral root discharges. Acta Physiol Scand 119:405-422.

Hultborn H, Malmsten J (1983b) Changes in segmental reflexes following chronic spinal cord hemisection in the cat. II. Conditioned monosynaptic test reflexes. Acta Physiol Scand 119:423-433.

Hussain ZM, Fitting S, Watanabe H, Usynin I, Yakovleva T, Knapp PE, Scheff SW, Hauser KF, Bakalkin G (2012) Lateralized response of dynorphin a peptide levels after traumatic brain injury. $J$ Neurotrauma 29:1785-1793.
Jabaily J, Davis JN (1984) Naloxone administration to patients with acute stroke. Stroke 15:36-39.

Jamal K, Leplaideur S, Rousseau C, Chochina L, Moulinet-Raillon A, Bonan I (2018) Disturbances of spatial reference frame and postural asymmetry after a chronic stroke. Exp Brain Res 236:23772385.

Jankowska E, Schomburg ED (1998) A leu-enkephalin depresses transmission from muscle and skin non-nociceptors to first-order feline spinal neurones. J Physiol 510:513-525.

Joynes RL, Janjua K, Grau JW (2004) Instrumental learning within the spinal cord: VI. The NMDA receptor antagonist, AP5, disrupts the acquisition and maintenance of an acquired flexion response. Behav Brain Res 154:431-438.

Kawakami R, Shinohara Y, Kato Y, Sugiyama H, Shigemoto R, Ito I (2003) Asymmetrical allocation of NMDA receptor epsilon2 subunits in hippocampal circuitry. Science 300:990-994.

Kononenko O, Galatenko V, Andersson M, Bazov I, Watanabe H, Zhou XW, latsyshyna A, Mityakina I, Yakovleva T, Sarkisyan D, Ponomarev I, Krishtal O, Marklund N, Tonevitsky A, Adkins DL, Bakalkin G (2017) Intra- and interregional coregulation of opioid genes: broken symmetry in spinal circuits. FASEB J 31:19531963.

Kononenko O, Mityakina I, Galatenko V, Watanabe H, Bazov I, Gerashchenko A, Sarkisyan D, latsyshyna A, Yakovleva T, Tonevitsky A, Marklund N, Ossipov MH, Bakalkin G (2018) Differential effects of left and right neuropathy on opioid gene expression in lumbar spinal cord. Brain Res 1695:78-83.

Lacalle-Aurioles M, Cassel de Camps C, Zorca CE, Beitel LK, Durcan TM (2020) Applying hiPSCs and biomaterials towards an understanding and treatment of traumatic brain injury. Front Cell Neurosci 14:594304.

Larsson M, Broman J (2008) Translocation of GluR1-containing AMPA receptors to a spinal nociceptive synapse during acute noxious stimulation. J Neurosci 28:7084-7090.

Light AR, Perl ER (1979) Reexamination of the dorsal root projection to the spinal dorsal horn including observations on the differential termination of coarse and fine fibers. J Comp Neurol 186:117-131.

Long Q, Argmann C, Houten SM, Huang T, Peng S, Zhao Y, Tu Z, GTEx Consortium, Zhu J (2016) Inter-tissue coexpression network analysis reveals DPP4 as an important gene in heart to blood communication. Genome Med 8:15.

Lorentzen J, Pradines M, Gracies JM, Bo Nielsen J (2018) On DennyBrown's 'spastic dystonia' - what is it and what causes it? Clin Neurophysiol 129:89-94.

MacNeilage PF, Rogers LJ, Vallortigara G (2009) Origins of the left and right brain. Sci Am 301:60-67.

Malmsten J (1983) Time course of segmental reflex changes after chronic spinal cord hemisection in the rat. Acta Physiol Scand 119:435-443.

Mansour A, Fox CA, Burke S, Meng F, Thompson RC, Akil H, Watson SJ (1994) Mu, delta, and kappa opioid receptor mRNA expression in the rat CNS: an in situ hybridization study. J Comp Neurol 350:412-438.

Marlin BJ, Mitre M, D'Amour JA, Chao MV, Froemke RC (2015) Oxytocin enables maternal behaviour by balancing cortical inhibition. Nature 520:499-504.

McElreath R (2019) Statistical rethinking. A Bayesian course with examples in $\mathrm{R}$ and Stan. London: Chapman and Hall/CRC.

Merg F, Filliol D, Usynin I, Bazov I, Bark N, Hurd YL, Yakovleva T, Kieffer BL, Bakalkin G (2006) Big dynorphin as a putative endogenous ligand for the kappa-opioid receptor. J Neurochem 97:292301.

Miller JF, Paul KD, Lee RH, Rymer WZ, Heckman CJ (1996) Restoration of extensor excitability in the acute spinal cat by the 5HT2 agonist DOI. J Neurophysiol 75:620-628.

Musienko PE, Zelenin PV, Orlovsky GN, Deliagina TG (2010) Facilitation of postural limb reflexes with epidural stimulation in spinal rabbits. J Neurophysiol 103:1080-1092. 
Namba S, Nishigaki S, Fujiwara N, Wani T, Namba Y, Masaoka T (1986) Opiate-antagonist reversal of neurological deficits-experimental and clinical studies. Jpn J Psychiatry Neurol 40:61-79.

Nation KM, De Felice M, Hernandez PI, Dodick DW, Neugebauer V, Navratilova E, Porreca F (2018) Lateralized kappa opioid receptor signaling from the amygdala central nucleus promotes stress-induced functional pain. Pain 159:919-928.

Ng SY, Lee AYW (2019) Traumatic brain injuries: pathophysiology and potential therapeutic targets. Front Cell Neurosci 13:528.

Nguyen XV, Masse J, Kumar A, Vijitruth R, Kulik C, Liu M, Choi DY, Foster TC, Usynin I, Bakalkin G, Bing G (2005) Prodynorphin knockout mice demonstrate diminished age-associated impairment in spatial water maze performance. Behav Brain Res 161:254-262.

Nizhnikov ME, Pautassi RM, Truxell E, Spear NE (2009) Opioid antagonists block the acquisition of ethanol-mediated conditioned tactile preference in infant rats. Alcohol 43:347-358.

Norris JN, Pérez-Acosta AM, Ortega LA, Papini MR (2009) Naloxone facilitates appetitive extinction and eliminates escape from frustration. Pharmacol Biochem Behav 94:81-87.

Nylander I, Stenfors C, Tan-No K, Mathé AA, Terenius L (1997) A comparison between microwave irradiation and decapitation: basal levels of dynorphin and enkephalin and the effect of chronic morphine treatment on dynorphin peptides. Neuropeptides 31:357-365.

O'Mahony A, Raber J, Montano M, Foehr E, Han V, Lu SM, Kwon H, LeFevour A, Chakraborty-Sett S, Greene WC (2006) NF-kappaB/ Rel regulates inhibitory and excitatory neuronal function and synaptic plasticity. Mol Cell Biol 26:7283-7298.

Patkar KA, Wu J, Ganno ML, Singh HD, Ross NC, Rasakham K, Toll L, McLaughlin JP (2013) Physical presence of nor-binaltorphimine in mouse brain over 21 days after a single administration corresponds to its long-lasting antagonistic effect on $\kappa$-opioid receptors. J Pharmacol Exp Ther 346:545-554.

Paxinos G, Watson C (2007) The rat brain in stereotaxic coordinates. San Diego: Academic Press.

Petkó M, Veress G, Vereb G, Storm-Mathisen J, Antal M (2004) Commissural propriospinal connections between the lateral aspects of laminae III-IV in the lumbar spinal cord of rats. J Comp Neurol 480:364-377.

Petrillo P, Angelici O, Bingham S, Ficalora G, Garnier M, Zaratin PF, Petrone G, Pozzi O, Sbacchi M, Stean TO, Upton N, Dondio GM, Scheideler MA (2003) Evidence for a selective role of the deltaopioid agonist [8R-(4bS*,8aalpha,8abeta, 12bbeta)]7,10-Dimethyl1-methoxy-11-(2-methylpropyl)oxycarbonyl 5,6,7,8,12,12b-hexahydro-(9H)-4,8-methanobenzofuro[3,2-e]pyrrolo[2,3-g]isoquinoli ne hydrochloride (SB-235863) in blocking hyperalgesia associated with inflammatory and neuropathic pain responses. J Pharmacol Exp Ther 307:1079-1089.

Phelps CE, Navratilova E, Dickenson AH, Porreca F, Bannister K (2019) Kappa opioid signaling in the right central amygdala causes hind paw specific loss of diffuse noxious inhibitory controls in experimental neuropathic pain. Pain 160:1614-1621.

Pilyavskii Al, Moska W, Kochanowicz K, Bulgakova NV, Maznychenko AV, Vereshchaka IV, Kostyukov Al (2013) Dynorphin $B$ induces lateral asymmetric changes in feline spinal cord reflexes. Front Neurosci 7:244.

Rossi A, Decchi B (1994) Flexibility of lower limb reflex responses to painful cutaneous stimulation in standing humans: evidence of load-dependent modulation. J Physiol 481:521-532.

Rutten K, Schröder W, Christoph T, Koch T, Tzschentke TM (2018) Selectivity profiling of NOP, MOP, DOP and KOP receptor antagonists in the rat spinal nerve ligation model of mononeuropathic pain. Eur J Pharmacol 827:41-48.

Sandrini G, Serrao M, Rossi P, Romaniello A, Cruccu G, Willer JC (2005) The lower limb flexion reflex in humans. Prog Neurobiol 77:353-395

Santibañez JF, Quintanilla M, Bernabeu C (2011) TGF- $\beta$ /TGF- $\beta$ receptor system and its role in physiological and pathological conditions. Clin Sci 121:233-251.
Schouenborg J (2002) Modular organisation and spinal somatosensory imprinting. Brain Res Brain Res Rev 40:80-91.

Schouenborg J, Holmberg H, Weng HR (1992) Functional organization of the nociceptive withdrawal reflexes. II. Changes of excitability and receptive fields after spinalization in the rat. Exp Brain Res 90:469-478.

Searle SR, Speed FM, Milliken GA (1980) Population marginal means in the linear model: an alternative to least squares means. Am Stat 34:216-221.

Serrao M, Ranavolo A, Andersen OK, Don R, Draicchio F, Conte C, Di Fabio R, Perrotta A, Bartolo M, Padua L, Santilli V, Sandrini G, Pierelli $F$ (2012) Reorganization of multi-muscle and joint withdrawal reflex during arm movements in post-stroke hemiparetic patients. Clin Neurophysiol 123:527-540.

Sheean G, McGuire JR (2009) Spastic hypertonia and movement disorders: pathophysiology, clinical presentation, and quantification. PM R 1:827-833.

Skarphedinsson JO, Delle M, Hoffman P, Thorén P (1989) The effects of naloxone on cerebral blood flow and cerebral function during relative cerebral ischemia. J Cereb Blood Flow Metab 9:515-522.

Spaich EG, Arendt-Nielsen L, Andersen OK (2004) Modulation of lower limb withdrawal reflexes during gait: a topographical study. J Neurophysiol 91:258-266.

Spaich EG, Hinge HH, Arendt-Nielsen L, Andersen OK (2006) Modulation of the withdrawal reflex during hemiplegic gait: effect of stimulation site and gait phase. Clin Neurophysiol 117:24822495.

Spaich EG, Svaneborg N, Jørgensen HR, Andersen OK (2014) Rehabilitation of the hemiparetic gait by nociceptive withdrawal reflex-based functional electrical therapy: a randomized, singleblinded study. J Neuroeng Rehabil 11:81.

Steffens H, Schomburg ED (2011) Spinal motor actions of the $\mu$-opioid receptor agonist DAMGO in the cat. Neurosci Res 70:44-54.

Tappe A, Klugmann M, Luo C, Hirlinger D, Agarwal N, Benrath J, Ehrengruber MU, During MJ, Kuner R (2006) Synaptic scaffolding protein Homer1a protects against chronic inflammatory pain. Nat Med 12:677-681.

Taylor SC, Nadeau K, Abbasi M, Lachance C, Nguyen M, Fenrich J (2019) The ultimate qPCR experiment: producing publication quality, reproducible data the first time. Trends Biotechnol 37:761774.

Vallortigara G, Rogers LJ (2020) A function for the bicameral mind. Cortex 124:274-285.

Vandesompele J, De Preter K, Pattyn F, Poppe B, Van Roy N, De Paepe A, Speleman F (2002) Accurate normalization of real-time quantitative RT-PCR data by geometric averaging of multiple internal control genes. Genome Biol 3:RESEARCH0034.

Vavrek R, Girgis J, Tetzlaff W, Hiebert GW, Fouad K (2006) BDNF promotes connections of corticospinal neurons onto spared descending interneurons in spinal cord injured rats. Brain 129:15341545.

Wang D, Tawfik VL, Corder G, Low SA, François A, Basbaum Al, Scherrer G (2018) Functional divergence of delta and mu opioid receptor organization in CNS pain circuits. Neuron 98:90-108.e5.

Wang X, Sun ZJ, Wu JL, Quan WQ, Xiao WD, Chew H, Jiang CM, Li $D(2019)$ Naloxone attenuates ischemic brain injury in rats through suppressing the NIK/IKK $\alpha / \mathrm{NF}-\kappa \mathrm{B}$ and neuronal apoptotic pathways. Acta Pharmacol Sinica 40:170-179.

Watanabe $H$, Fitting $S$, Hussain $M Z$, Kononenko $O$, latsyshyna A, Yoshitake T, Kehr J, Alkass K, Druid H, Wadensten H, Andren PE, Nylander I, Wedell DH, Krishtal O, Hauser KF, Nyberg F, Karpyak VM, Yakovleva T, Bakalkin G (2015) Asymmetry of the endogenous opioid system in the human anterior cingulate: a putative molecular basis for lateralization of emotions and pain. Cereb Cortex 25:97-108.

Watanabe H, Nosova O, Sarkisyan D, Andersen MS, Zhang M, Rorick-Kehn L, Clausen F, Gawel K, Kehr J, Hallberg M, Schouenborg J, Marklund N, Bakalkin G (2020) Ipsilesional versus contralesional postural deficits induced by unilateral brain trauma: a side reversal by opioid mechanism. Brain Commun 2:fcaa208. 
Weng HR, Schouenborg J (1996) Cutaneous inhibitory receptive fields of withdrawal reflexes in the decerebrate spinal rat. J Physiol 493:253-265.

Weng HR, Schouenborg J (1998) On the cutaneous receptors contributing to withdrawal reflex pathways in the decerebrate spinal rat. Exp Brain Res 118:71-77.

Wilson L, Stewart W, Dams-O'Connor K, Diaz-Arrastia R, Horton L, Menon DK, Polinder S (2017) The chronic and evolving neurological consequences of traumatic brain injury. Lancet Neurol 16:813825.

Won S, Incontro S, Nicoll RA, Roche KW (2016) PSD-95 stabilizes NMDA receptors by inducing the degradation of STEP61. Proc Natl Acad Sci USA 113:E4736-E4744.

You HJ, Mørch CD, Arendt-Nielsen L (2004) Electrophysiological characterization of facilitated spinal withdrawal reflex to repetitive electrical stimuli and its modulation by central glutamate receptor in spinal anesthetized rats. Brain Res 1009:110-119.

Zhang M, Watanabe H, Sarkisyan D, Andersen MS, Nosova O, Galatenko V, Carvalho L, Lukoyanov N, Thelin J, Schouenborg J, Bakalkin G (2020) Hindlimb motor responses to unilateral brain injury: spinal cord encoding and left-right asymmetry. Brain Commun 2:fcaa055.

Zhou HH, Jin TT, Qin B, Turndorf H (1998) Suppression of spinal cord motoneuron excitability correlates with surgical immobility during isoflurane anesthesia. Anesthesiology 88:955-961.

Zink CF, Kempf L, Hakimi S, Rainey CA, Stein JL, Meyer-Lindenberg A (2011) Vasopressin modulates social recognition-related activity in the left temporoparietal junction in humans. Transl Psychiatry 1: e3. 